\title{
Enhancement of Photosynthetic Iron-Use Efficiency Is an Important Trait of Hordeum vulgare for Adaptation of Photosystems to Iron Deficiency
}

\author{
Akihiro Saito *, Shotaro Shinjo, Daiki Ito, Yuko Doi, Akira Sato, Yuna Wakabayashi, Juma Honda, Yuka Arai, \\ Tsubasa Maeda, Takuji Ohyama and Kyoko Higuchi (D)
}

check for updates

Citation: Saito, A.; Shinjo, S.; Ito, D.; Doi, Y.; Sato, A.; Wakabayashi, Y.;

Honda, J.; Arai, Y.; Maeda, T.;

Ohyama, T.; et al. Enhancement of Photosynthetic Iron-Use Efficiency Is an Important Trait of Hordeum vulgare for Adaptation of Photosystems to Iron Deficiency. Plants 2021, 10, 234. https: / / doi.org/10.3390/ plants10020234

Received: 7 October 2020

Accepted: 18 January 2021

Published: 25 January 2021

Publisher's Note: MDPI stays neutra with regard to jurisdictional claims in published maps and institutional affiliations.

Copyright: (c) 2021 by the authors. Licensee MDPI, Basel, Switzerland. This article is an open access article distributed under the terms and conditions of the Creative Commons Attribution (CC BY) license (https:// creativecommons.org/licenses/by/ $4.0 /)$.
Laboratory of Biochemistry in Plant Productivity, Department of Agricultural Chemistry, Tokyo University of Agriculture, Setagaya-ku, Tokyo 156-8502, Japan; hxmelt@gmail.com (S.S.); daiki.medamaoyazi@ezweb.ne.jp (D.I.); i-8yk.s4@ezweb.ne.jp (Y.D.); s.akira-0926@i.softbank.jp (A.S.); 44419021@nodai.ac.jp (Y.W.); asarihonda@yahoo.co.jp (J.H.); ar23yu@icloud.com (Y.A.); tm.nm7-28346@docomo.ne.jp (T.M.); to206474@nodai.ac.jp (T.O.); khiguchi@nodai.ac.jp (K.H.)

* Correspondence: a3saito@nodai.ac.jp; Tel.: +81-3-5477-2306

\begin{abstract}
Leaf iron (Fe) contents in Fe-deficiency-tolerant plants are not necessarily higher than that in Fe-deficiency-susceptible ones, suggesting an unknown mechanism involved in saving and allowing the efficient use of minimal Fe. To quantitatively evaluate the difference in Fe economy for photosynthesis, we compared the ratio of $\mathrm{CO}_{2}$ assimilation rate to Fe content in newly developed leaves as a novel index of photosynthetic iron-use efficiency (PIUE) among 23 different barley (Hordeum vulgare L.) varieties. Notably, varieties originating from areas with alkaline soil increased PIUE in response to Fe-deficiency, suggesting that PIUE enhancement is a crucial and genetically inherent trait for acclimation to Fe-deficient environments. Multivariate analyses revealed that the ability to increase PIUE was correlated with photochemical quenching (qP), which is a coefficient of light energy used in photosynthesis. Nevertheless, the maximal quantum yield of photosystem II (PSII) photochemistry, non-photochemical quenching, and quantum yield of carbon assimilation showed a relatively low correlation with PIUE. This result suggests that the ability of Fe-deficiencytolerant varieties of barley to increase PIUE is related to optimizing the electron flow downstream of PSII, including cytochrome $b_{6} f$ and photosystem I.
\end{abstract}

Keywords: photosynthetic iron (Fe)-use efficiency; iron deficiency; barley; sorghum; Fe economy; electron transport chain; photosystem I; photosystem II

\section{Introduction}

Photosynthesis is the most Fe (iron)-requiring process in plants [1]. The initial reaction in photosynthesis is the photosynthetic electron transfer that converts light energy into chemical energy between photosystems I and II (PSI and PSII) via cytochrome (cyt) $b_{6} f$ in thylakoid membranes. During this process, most of the Fe is distributed into [4Fe-4S] cluster-containing PSI and Fe-containing cyt $b_{6} f$ complexes and mediates light-driven electron transfer [1-3].

In plants suffering from Fe-deficiency, toxic reactive oxygen species are generated because of the overreduction of the plastoquinone pool due to the decrease in the Fecontaining cyt $b_{6} f$ and PSI function $[4,5]$. Fe-deficiency in plants often occurs in calcareous alkaline soils. At a high $\mathrm{pH}$ in calcareous soil, the equilibrium concentration of total dissolved $\mathrm{Fe}$ is considerably less than the concentration required for optimal growth of plants in nutrient culture [6,7]. These alkaline soils are widely distributed globally, and it is therefore crucial to understand the photosynthetic system with high Fe-use efficiency for the increase in plant biomass in such environments [5]. 
Of the crop plants, barley (Hordeum vulgare L.) is characterized as having a relatively high Fe-deficiency-tolerance. The mechanisms underlying this tolerance are coordinated in both the roots and shoots. In roots, barley has a remarkable ability to secrete mugineic acid family phytosiderophores (MAs) [8-10]. The MAs secreted from roots to the rhizosphere dissolve insoluble Fe by chelating and contribute significantly to the Fe-deficiency-tolerance of this plant [8]. In the shoots, barley continues growth under prolonged Fe-deficiency with less MAs and its precursor nicotianamine [11], with a similar Fe content compared to Fe-deficiency-susceptible rice [12,13], suggesting that adaptive mechanisms exist in the photosynthetic tissues of barley to cope with the Fe-deficiency.

In the analysis of Fe-deficient barley shoots, multiple adaptive mechanisms for Fedeficiency have been found in shoots. For instance, Fe-deficient barley demonstrates the ability to relocate $\mathrm{Fe}, \mathrm{N}$, and $\mathrm{C}$ effectively, accelerating the senescence of the lower leaves to compensate for the reduced photosynthesis in the young chlorotic leaves [12,14-16]. In chloroplasts of Fe-deficient barley, Fe is preferentially distributed into the thylakoid membranes [17]. Furthermore, prolonged Fe-deficiency (more than two weeks) induces non-photochemical quenching (NPQ), in which the excess-absorbed light energy is dissipated into heat, with the phosphorylation and monomerization of HvLhcb1, a major light-harvesting antenna protein of PSII. This NPQ induction results in protection from the photo-inhibitory effect caused by Fe-deficiency $[13,18]$. We propose that these features allow barley to sustain photosynthesis under long-term Fe-deficient conditions. However, the universality of these mechanisms and diversity of Fe-deficiency-tolerance in $H$. vulgare varieties is still unclear.

Barley is one of the oldest crops and has been cultivated for over 10,000 years [19]. Critical genes related to stress adaptation and domestication have been identified in recent years by new genetic analysis using the natural variation of barley [19-22]. To apply these molecular genetic approaches to study the adaptative mechanisms of photosynthesis to Fe-deficiency in barley, the appropriate quantitative traits to evaluate Fe-use efficiency are needed.

Many studies have quantified the nitrogen $(\mathrm{N})$ demand for photosynthesis among various species, using the index "photosynthetic N-use efficiency (PNUE)". PNUE is calculated as the photosynthetic capacity per leaf $\mathrm{N}$ content and has been studied as an important leaf trait [23]. This index is convenient and useful because it can be determined in a small leaf area regardless of growth conditions. To date, various comparative studies of PNUE have been conducted among a wide range of plant species [24-27]. Through these studies, PNUE has been identified as an inherent trait of a species and is associated with multiple physiological factors, including $\mathrm{CO}_{2}$ diffusion, ribulose-1,5-bisphosphate carboxylase/oxygenase (RuBisCO) activity, and N partitioning in chloroplasts [23]. Although the concept of PNUE has been applied to other macronutrients, there is no example of applying this concept to the study of micronutrient use efficiency in plants.

In this study, we investigated the photosynthetic Fe-use efficiency (PIUE) to elucidate the difference in the Fe economy among barley varieties grown under the long-term Fe-deficient condition. We could determine PIUE appropriately by a simple method to calculate the ratio of the net $\mathrm{CO}_{2}$ assimilation rate to Fe content in the leaf as an index analogous to PNUE. Different barley varieties originating from regions covered with various soil $\mathrm{pH}$ values were selected to reveal the genetic variation in PIUE. Based on the comparison of the photosynthetic function among barley varieties with different PIUE properties, a link between PIUE and the function of the photosynthetic electron transport chain downstream of PSII to PSI is proposed. 


\section{Results}

2.1. Fe-Deficiency-Tolerance within Barley Varieties Was Not Related to the Total Fe Content in Leaves

Barley (H. vulgare) is known to be more tolerant of Fe-deficiency than other crop plants. However, Fe-deficiency-tolerance within a wide range of barley subspecies has not been comparatively analyzed. In this study, we first evaluated the variation in Fedeficiency-tolerance in $H$. vulgare species. For this purpose, four cultivars, SRB1 (Iranian), EHM1 (Japanese), ETH2 (Ethiopian), and MSS (Japanese), showing significant differences in growth under Fe-deficiency, were selected from various barley varieties (list of the full names of cultivars is in Section 4.1 and Supplementary Table S1).

Our previous study [13] had shown that long-term Fe-deficiency for more than 16 days induces the photosynthetic acclimation in the young developed leaves at fifth to sixth leaf positions. To evaluate their tolerance to the long-term Fe-deficient condition, young seedlings were transferred to the hydroponic solutions with Fe concentrations of $1-30 \mu \mathrm{M}$ for 16 days. Then, the extent of Fe-deficient chlorosis was evaluated by analyzing the Soil Plant Analysis Development (SPAD, leaf chlorophyll meter) values in the young expanded leaves at the fifth leaf position (Figure 1).

Among the four cultivars tested, SRB1, an Fe-deficiency-tolerant variety, did not show any chlorosis even under $1 \mu \mathrm{M}$ Fe-deficient condition for 16 days (Figure 1A), and maintained SPAD over 50 under every Fe treatment condition (Figure 1B). Another Fe-deficiency-tolerant cultivar, EHM1, also showed no distinct Fe-deficiency chlorosis when grown in the hydroponic solution containing $3 \mu \mathrm{M}$ Fe (Figure $1 \mathrm{~A}$ ). Under $1 \mu \mathrm{M}$ Fe-deficient condition, EHM1 showed mild chlorosis with the SPAD value of $58 \%$ relative to control plants grown under $30 \mu \mathrm{M}$ Fe-sufficient condition (Figure 1A,B). In contrast, Fe-deficiency-susceptible ETH2 and MSS showed clear chlorosis when grown under Fe concentrations below $3 \mu \mathrm{M}$ (Figure 1A,B). We further confirmed that the order of Fedeficiency-tolerance based on SPAD value and shoot biomass was SRB1 > EHM1 > ETH2 > MSS1 under more severe Fe-deficient condition (grown under hydroponic solution without Fe) (Supplementary Figure S1A,B). Hence, contrary to the shared recognition that barley is a plant species with high Fe-deficiency-tolerance, $H$. vulgare species have a considerably large variation in Fe-deficiency-tolerance, which is sufficient to study the genetic diversity of Fe-deficiency-tolerance.

In this experiment, we also evaluated the Fe content in roots and every leaf of four barley cultivars (Supplementary Figure S2). However, the results showed no clear relationship between the order of Fe-deficiency-tolerance and Fe content in each tissue. Similarly, there was no regularity in the Fe distribution in all tissues of roots and shoots under Fe-deficiency within these barley subspecies (Supplementary Figure S3). These results raised the new possibility that the factor responsible for Fe-deficiency-tolerance among barley varieties is not merely related to total Fe content in leaves or the distribution patterns. 
A

\section{Fe treatment $(\mu \mathrm{M})$}
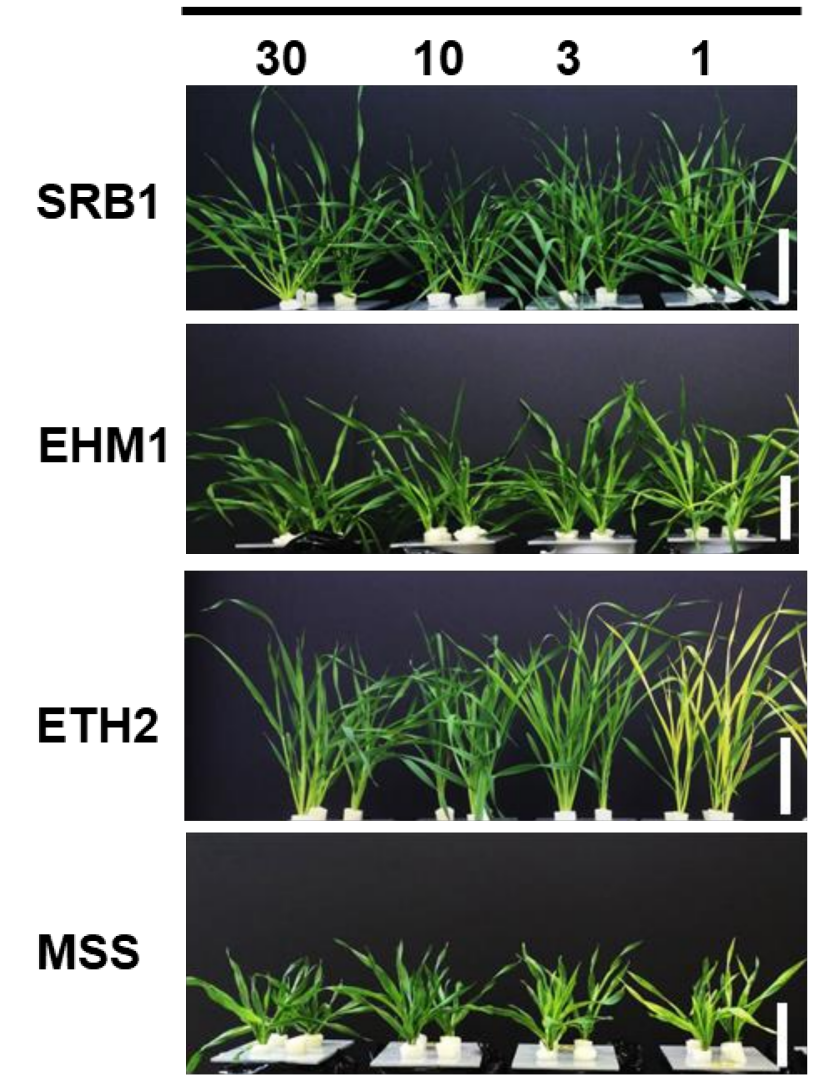

B

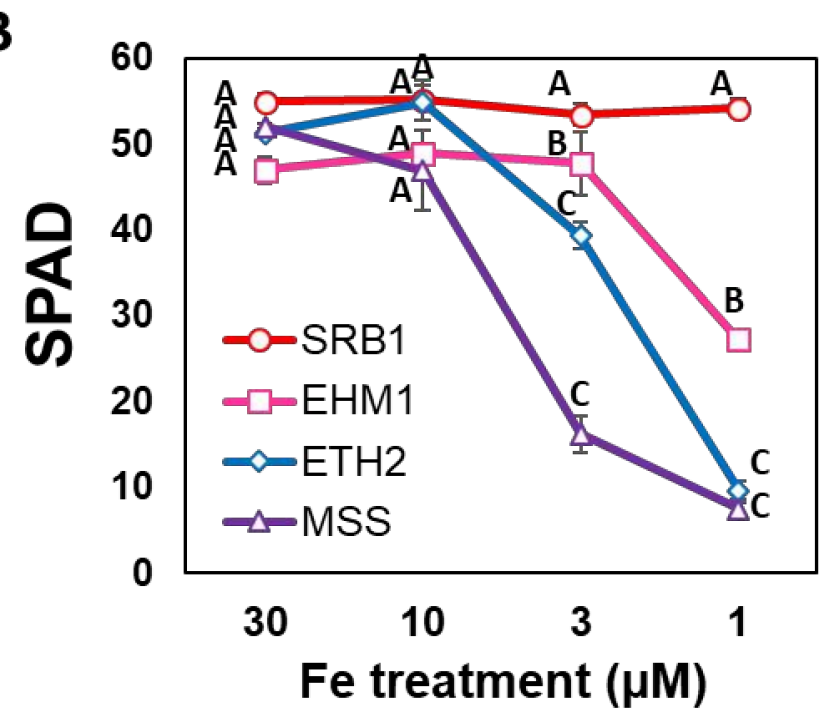

Figure 1. Fe-deficiency-tolerance among four representative barley varieties. Photographs (A) and SPAD (chlorophyll meter) values of young developed leaves $(\mathbf{B})$ of four barley varieties grown under different Fe treatment (30, 10, 3, and $1 \mu \mathrm{M} \mathrm{Fe}$ ) for 16 days. Before the Fe treatments, seedlings were grown with normal Fe concentration $(30 \mu \mathrm{M} \mathrm{Fe})$ for 11-12 days as a pre-culture until the seed nutrition was consumed. Significant differences among different varieties were tested using the Tukey's multiple test at each Fe treatment $(\mathrm{N}=3 \pm$ standard error, $p<0.05$, same letters indicate no significant difference). 'Sarab 1' (SRB1) and 'Ehime Hadaka 1' (EHM1) are the tolerant cultivars and 'Ethiopia 2' (ETH2) and 'Musashinomugi' (MSS) are the susceptible barley cultivars. 


\subsection{Thylakoid Fe Concentration Was Not Correlated with Photosynthesis under Fe-Deficient Conditions}

Next, we evaluate the function of photosynthetic electron transport among the four representative varieties to explore the factors affecting Fe-deficiency-tolerance among barley varieties. Because light absorption patterns and Fe content may differ significantly in leaves with different amounts of chlorophyll, we conducted this experiment by minimizing the differences in chlorophyll content among barley varieties under Fe-deficiency. For this purpose, we modified the Fe concentration in the hydroponic solution for each variety to adjust the SPAD value in the newly developed leaves (fifth to sixth leaves) under Fe-deficient conditions. The pre-cultivation and Fe treatment periods were kept constant to be the same for all varieties because the photosynthetic function of higher plants cannot be precisely evaluated without the same leaf age and the same cultivation period. This cultivation method with modified Fe concentration in medium has been a reliable method to assess the photosynthetic function in analyzing plants with different Fe-deficiency-tolerance [13,17].

After cultivation in the hydroponic solutions with $3.0 \mu \mathrm{M}$ Fe-ethylenediaminetetraacetic acid (EDTA) for ETH2 and MSS, and $0.5 \mu \mathrm{M}$ for SRB1 and EHM1, SPAD values of the fifth developed leaves in the four cultivars under Fe-deficiency were comparable after the 16 days of Fe-deficiency (Figure 2A). In this treatment, Fe concentrations in the young, fully expanded leaves, and the isolated thylakoid membranes, were also comparable in all cultivars under Fe-sufficient or Fe-deficient conditions (Figure 2B,C). Although all four barley varieties showed an increase in thylakoid Fe concentrations due to Fe-deficiency based on chlorophyll content, as previously reported [17], such preferential Fe distribution to the thylakoid membranes is apparently common in all varieties.

On the other hand, the quantum efficiencies of PSII electron transport ( $\varphi$ PSII) were lower in the Fe-deficiency-susceptible varieties (ETH2 and MSS) than in the Fe-deficiencytolerant varieties (SRB1 and EHM1) (Figure 2D). Of note, even though the Fe-deficiencysusceptible ETH2 and MSS have the advantage of being grown in the medium containing higher $\mathrm{Fe}(3.0 \mu \mathrm{M}$ Fe-EDTA) compared to the medium for the tolerance varieties $(0.5 \mu \mathrm{M}$ FeEDTA), they were still photosynthetically inferior to both SRB1 and EHM1. In other words, the slightly alleviating Fe-deficiency treatment for the susceptible varieties (ETH2 and MSS) could not improve the inferior photosynthetic function to the level of the tolerant varieties (SRB and EHM1), suggesting that Fe-deficiency-susceptible ETH2 and MSS require more Fe to maintain photosynthesis. Taken together, this result implied that there was a significant difference between these cultivars in the Fe-use efficiency for photosynthesis independent of the leaf color and amount of Fe accumulation under Fe-deficiency.

To confirm whether leaf Fe content itself is unrelated to Fe-deficiency-tolerance among barley varieties, we expanded the number of analyzed barley varieties listed in Supplementary Table S1. The newly developed leaves of 23 varieties were analyzed to determine the net $\mathrm{CO}_{2}$ assimilation rate and Fe concentration after 16 days of hydroponic culture with $30 \mu \mathrm{M}$ Fe or without Fe (Supplementary Figure S4). The results of the comparison of these barley varieties originating from different regions in the world revealed that there was no correlation between leaf Fe content and photosynthetic $\mathrm{CO}_{2}$ assimilation rate under both Fe-sufficient and Fe-deficient conditions (Figure 3A,B). As the most prominent example, MSS in the Fe-deficient condition showed almost no assimilation of $\mathrm{CO}_{2}\left(0.18 \mu \mathrm{mol} \mathrm{CO} \mathrm{Cm}^{-2} \mathrm{~s}^{-1}\right)$, although MSS had the highest Fe content $\left(44 \mu \mathrm{mol} \mathrm{Fe} \mathrm{m}{ }^{-2}\right.$ leaf), confirming that this Fe-deficiency-susceptible variety has very low Fe-use efficiency for photosynthesis. 

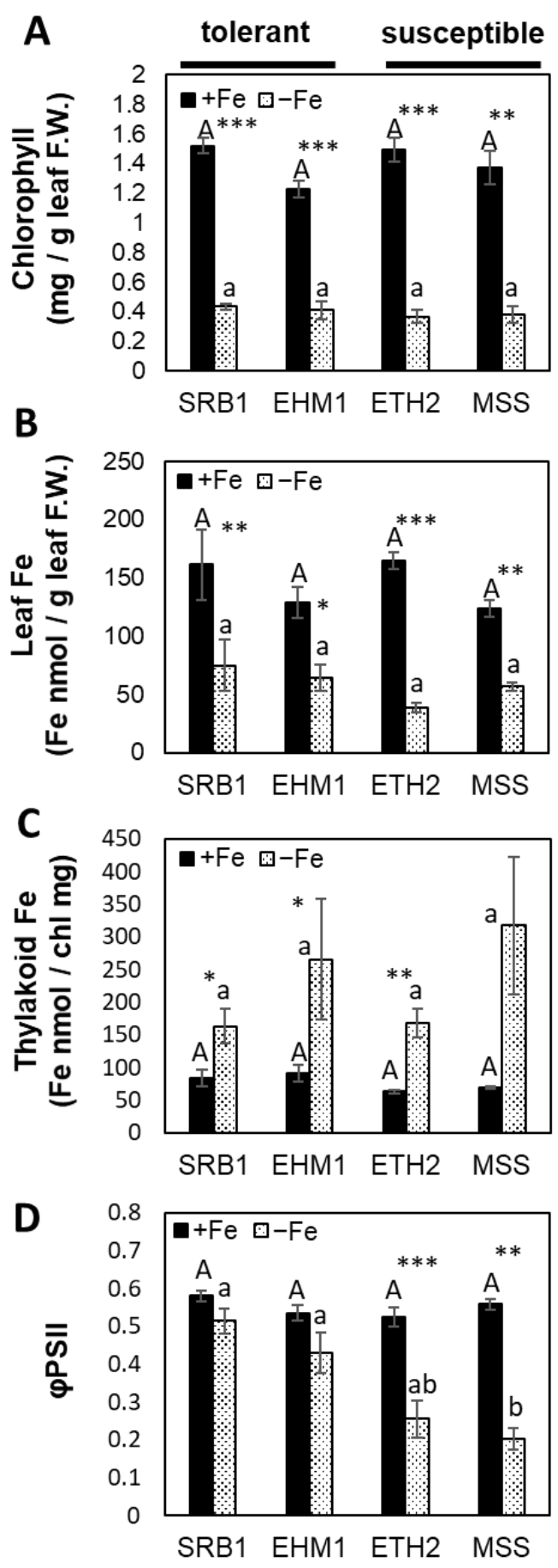

Figure 2. Comparison of the physiological traits among four representative barley varieties. Data were obtained from young developed leaves (5-6th leaves) of each variety. Chlorophyll concentrations (A), Fe concentrations in leaf (B), Fe concentrations in the thylakoid membranes (C), and chlorophyll fluorescence parameter for the quantum efficiencies of PSII electron transport ( $\varphi$ PSII) (D) of four barley varieties grown under Fe-sufficient $(+\mathrm{Fe})$ and mild Fe-deficient $(-\mathrm{Fe})$ conditions for 16-20 days are shown. Fe concentration in the - Fe solution was adjusted to $3.0 \mu \mathrm{M}$ Fe for ETH2 and MSS, and $0.5 \mu \mathrm{M}$ Fe for SRB1 and EHM1 to prepare similar chlorotic leaves at the fifth leaf position in all four cultivars. The significant differences between Fe treatments were determined using the Student's $t$-test $\left(\left(\mathrm{N}=3 \pm\right.\right.$ standard error, $\left.^{*} p<0.05,{ }^{* *} p<0.01,{ }^{* * *} p<0.001\right)$, and between-varieties Tukey's multiple test was used $(p<0.05$, no significant difference between the same lowercase or between the same capital letters). 

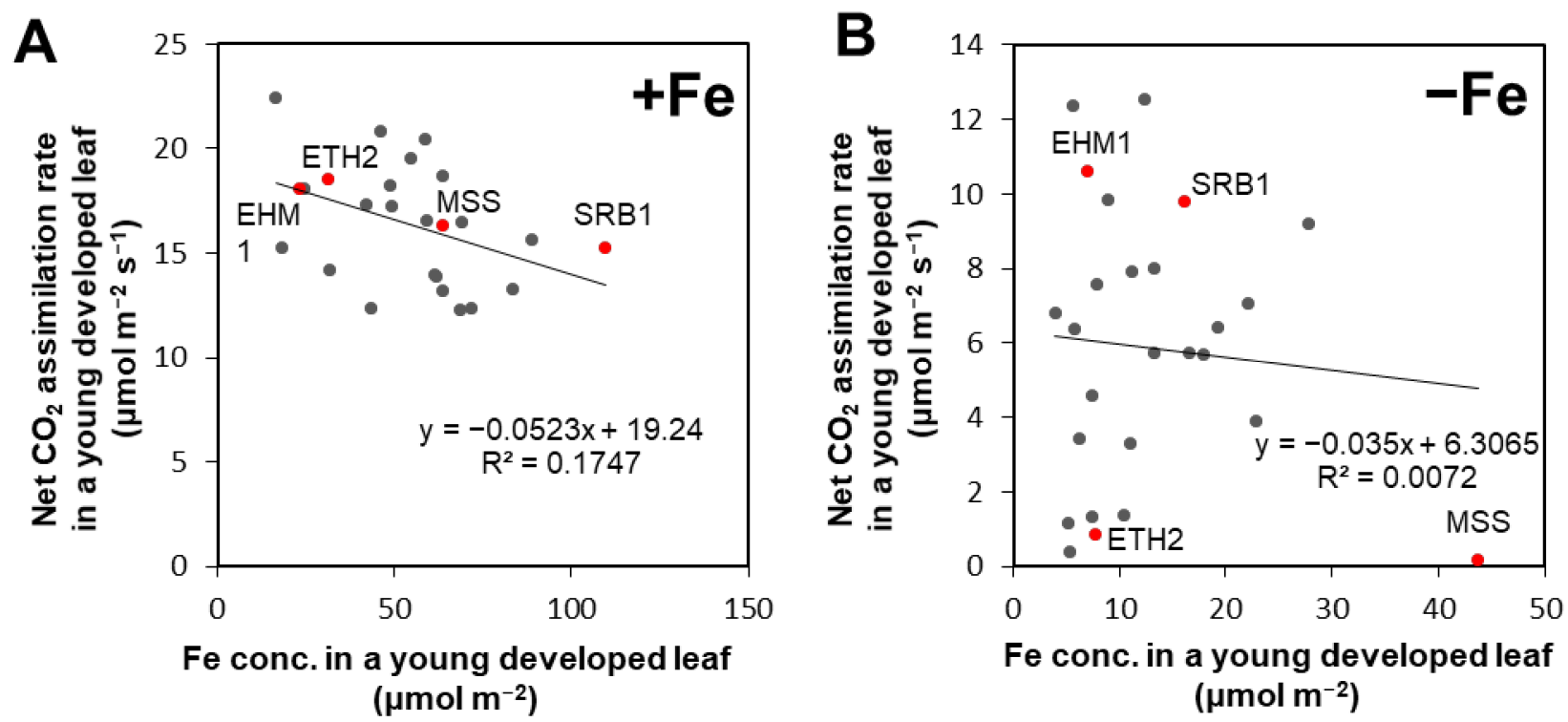

Figure 3. Correlation between leaf Fe concentration and net $\mathrm{CO}_{2}$ assimilation rate among barley varieties. Correlation data among 23 barley varieties grown under Fe-sufficient (+Fe) condition (A) or Fe-deficient ( $-\mathrm{Fe})$ condition (B). The original data on barley (including H. vulgare spontaneum and Hordeum murinum) used for the analysis are presented in Supplementary Figure S4. Significance of differences in Pearson's correlation coefficient between treatment groups was determined using the Student's $t$-test ( $p<0.05$, no notation for those with no significant difference). 'Sarab 1' (SRB1) and 'Ehime Hadaka 1' (EHM1) are the tolerant cultivars, and 'Ethiopia 2' (ETH2) and 'Musashinomugi' (MSS) are the susceptible barley cultivars.

\subsection{Evaluation of 'Photosynthetic Fe-Use Efficiency (PIUE)'}

To evaluate the difference in Fe-use efficiency in photosynthesis, we compared the $\mathrm{CO}_{2}$ assimilation rate and Fe content in one newly developed leaf among barley varieties from a diverse geographical area (Supplementary Table S1). After the dataset was obtained, we calculated the $\mathrm{CO}_{2}$ assimilation rate per unit Fe content in the same leaves (Supplementary Figure S4). The calculated value was denoted as photosynthetic iron-use efficiency, PIUE (Figure 4A), analogous to the index of the photosynthetic nitrogen-use efficiency, PNUE.

Interestingly, the PIUE varied among varieties even under Fe-sufficient conditions, but the difference was more evident under Fe-deficient conditions (absolute PIUE in Figure 4A). Eight barley varieties (TW25, TRP, SRB1, AGR, GLD, EHM1, CLN, and KTN1) and the related species, Hordeum murinum, increased PIUE or maintained a high level of PIUE in Fe-deficient conditions compared to under Fe-sufficient conditions. In contrast, the other five barley varieties (MSS, Spont-Fin, ETH2, BNS, IGR, and MRX) exhibited a decrease in PIUE to less than half under Fe-deficiency, indicating that the photosynthetic function of these varieties seems to be highly susceptible to Fe-deficiency (Figure 4A).

Compared to $\mathrm{CO}_{2}$ assimilation rate, the respiration rates in all cultivars were maintained relatively high in the Fe-deficient leaves (Supplementary Table S2), confirming that we could make measurements on active young developed leaves that had not undergone necrosis or senescence. To guarantee the reproducibility of PIUE analysis, a representative barley variety, EHM1, was grown in three batches by different experimenters at different times to obtain independent data in triplicate (Figure 4A, EHM1(1)-(3)). The relative PIUE values (not absolute PIUE values) of three different cultivation batches, EHM1(1), (2), and (3), tended to be the same with nearly identical values (Figure 4A), even though the photosynthetic rate and Fe content varied among the independent growing batches (Supplementary Figure S4A,B). This result indicates that the relative PIUE, i.e., the fold changes between the PIUE of Fe-deficient leaves and Fe-sufficient leaves, is a very reliable and specific value for each variety. 


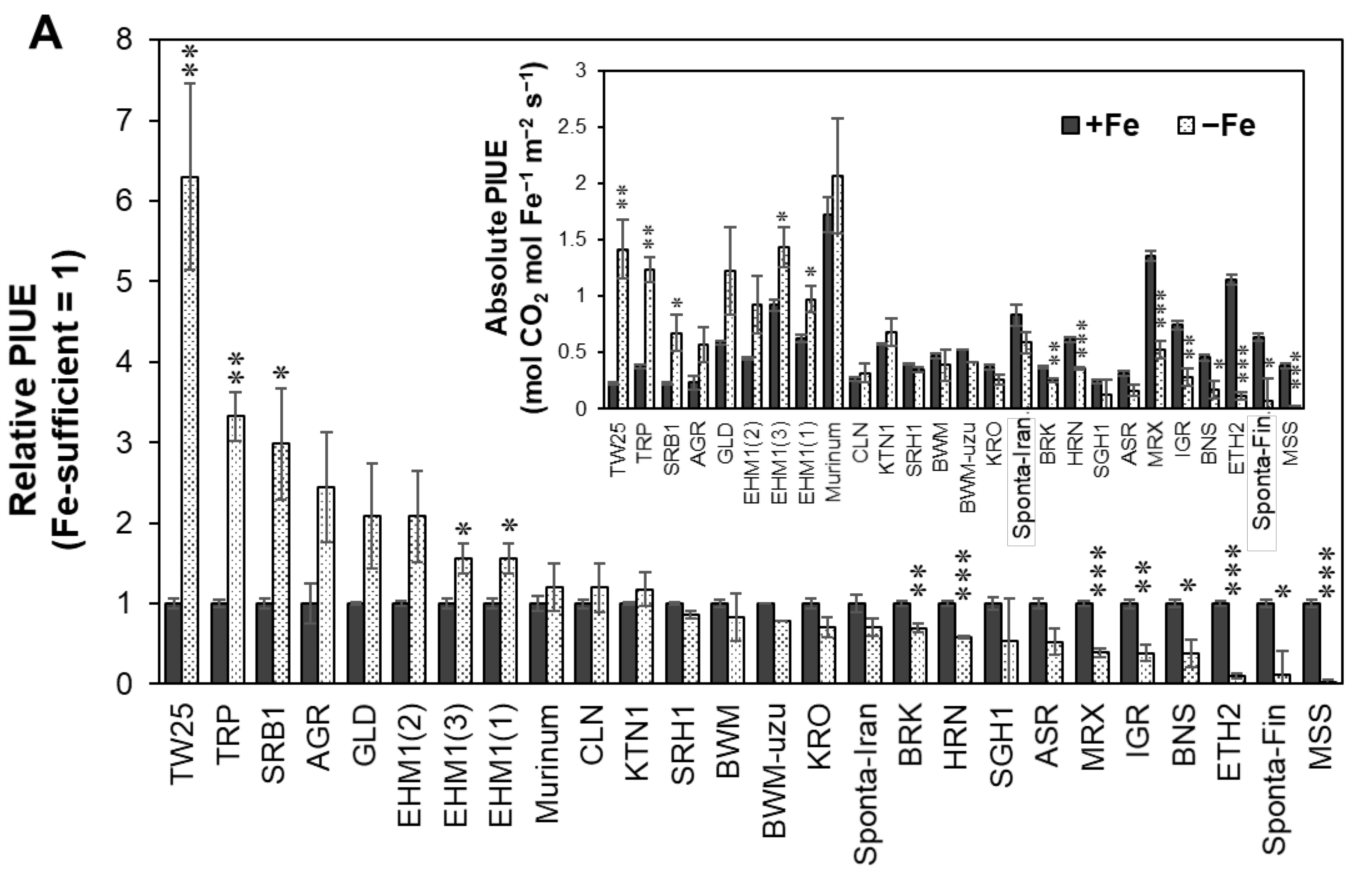

Barley varieties
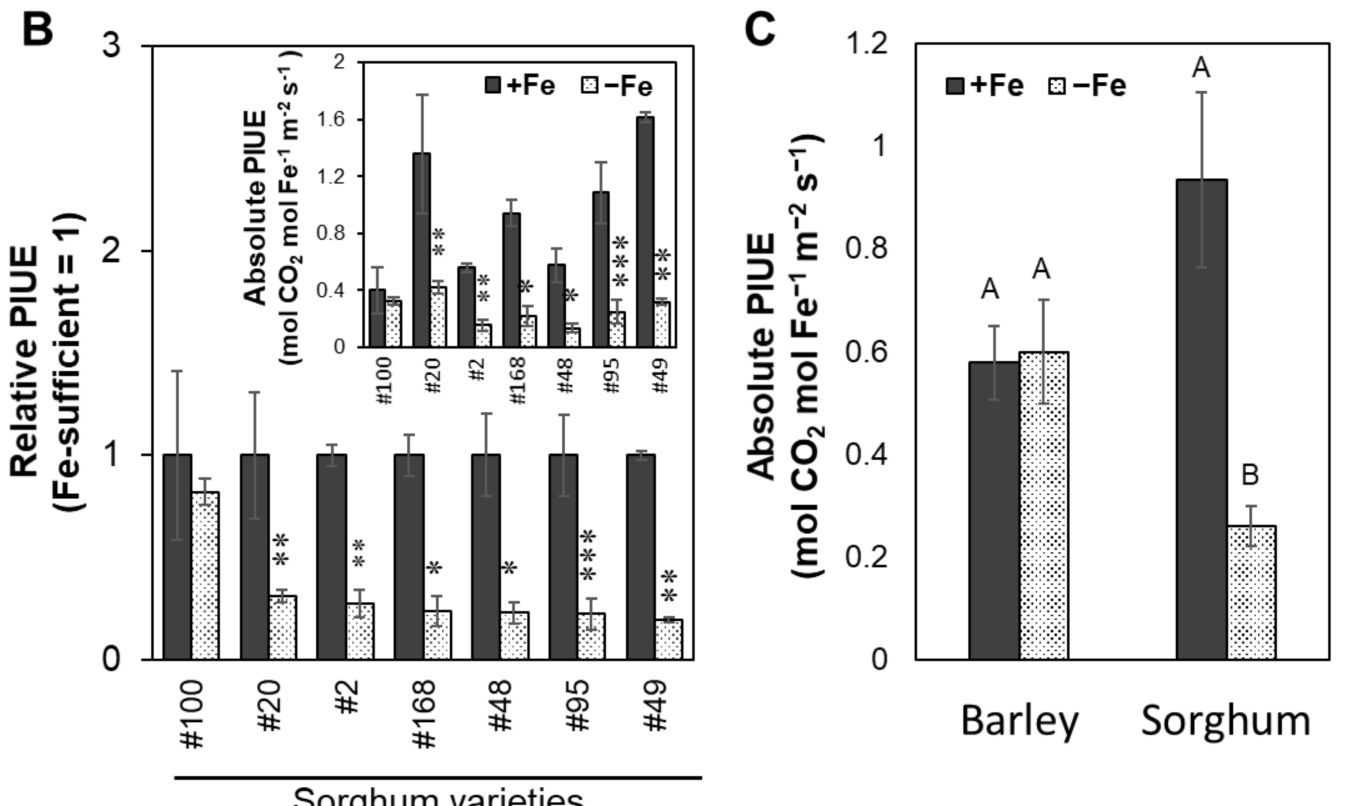

Sorghum varieties

Figure 4. Variation in the photosynthetic Fe-use efficiency (PIUE) among barley and sorghum varieties. The relative value of PIUE of the Fe-deficient ( $-\mathrm{Fe}$ ) leaves to the Fe-sufficient $(+\mathrm{Fe})$ leaves of barley (A) and sorghum (B) are shown. Inserted figures in $(\mathbf{A}, \mathbf{B})$ are absolute value of PIUE, representing molar amounts of $\mathrm{CO}_{2}$ that can be assimilated per mole leaf Fe in one second of time. Comparison of an average of absolute PIUE values for all barley and all sorghum varieties (C). The significant differences between Fe-sufficient and Fe-deficient plants in $(\mathbf{A}, \mathbf{B})$ were tested using the Student's $t$-test $(\mathrm{N}=3 \pm$ standard error, $\left.{ }^{*} p<0.05,{ }^{* *} p<0.01,{ }^{* * *} p<0.001\right)$, and among the data of sorghum and barley in (C) were tested using the Tukey's multiple test $(\mathrm{N}=3 \pm$ standard error, $p<0.05$, same capital letters indicate no significant difference). Abbreviations of plant variety names are summarized below: 'Ehime Hadaka 1' (EHM1), 'Shiro Hadaka 1' (SRH1), 'Kairyo Ogara' (KRO), 'Haruna Nijo' (HRN), 'Akashinriki' (ASR), 'Saga Hadaka 1' (SGH1), 'Musashinomugi' (MSS), 'Colonial' (CLN), 'Bowman' (BWM), 'Bowman near-isogenic line uzu1.a' (BWM-uzu), 'Bonus (BNS), 'Igri' (IGR), 'Barke' (BRK), 'Morex' (MRX), 'Golden Promise' (GLD), 'Tripoli' (TRP), 'Sarab 1' (SRB1), 'Katana 1' (KTN1), 'Tibet White 25' (TW25), 'Ethiopia 2' (ETH2), 'Agriochriton' (AGR), 'Spontaneum' from Iran (Sponta-Iran), 'Spontaneum' from Finland (Sponta-Fin), and Hordeum murinum L. (Murinum). Triplicate data of EHM1 are denoted as (EHM1(1), EHM1(2), and EHM1(3)). 
With the aim of determining whether PIUE can quantitatively detect the Fe economy in chloroplasts among different plant species, we also investigated the PIUE among C4 graminaceous sorghum varieties. We have already reported that sorghum, unlike barley, is a plant species that cannot increase Fe allocation to thylakoid membranes under Fedeficiency and is relatively less efficient in Fe use in the chloroplasts [17]. As expected, PIUE decreased in almost all varieties of sorghum with Fe-deficiency, except for one variety ('\#100') (Figure 4B). Although the average PIUE value of all sorghum varieties under Fesufficient conditions was slightly (not significantly) higher than that of barley, the value in Fe-deficient conditions was decreased significantly to only about half the level of the barley varieties (Figure $4 \mathrm{C}$ ). These results indicate that PIUE is a very effective indicator for quantifying differences in the Fe-deficiency responses of chloroplasts among plant species.

\subsection{Genetic Diversity of PIUE in Barley Is the Result of Selection on Alkaline Soils}

For an ecological perspective, we plotted the barley varieties in the world soil $\mathrm{pH}$ map created based on the Harmonized World Soil Database (HWSD) (Figure 5A). The HWSD map has been used as the most comprehensive, detailed, and updated global soil database currently available [28]. In this study, most of the barley used is cultivated and widely grown in vast areas of each country or regions. HWSD provides a raster map with $1 \mathrm{~km}$ spatial resolution, which is accurate enough to estimate the soil environment of the growing area. Among the eight domesticated H. vulgare varieties showing increased PIUE under Fe-deficiency, five varieties, TW25, TRP, SRB1, AGR, and KTN1, were originally developed in regions with alkaline soil (average soil $\mathrm{pH}$ above 6.5). In addition, EHM1, which is another variety with increased PIUE under Fe-deficiency, was developed in an area with relatively high soil pH (average soil pH above 6.0) in Japan (Figure 5A and Supplementary Table S1). In contrast, all varieties with low PIUE under Fe-deficiency, such as MSS, ETH2, BNS, IGR, MRX, SGH1, and ASR, originated from regions of acidic soil (average soil pH below 5.5). Therefore, a significant increase in relative PIUE can be observed in varieties developed in regions with calcareous alkaline soils such as China, Tibet, the Middle East, and the Mediterranean (Figure 5B). The same conclusion was drawn by sorting varieties based on soil $\mathrm{pH}$ (Figure $5 \mathrm{C}$ ). The distribution pattern of barley varieties on the world soil map (Figure 5A) implies that soil $\mathrm{pH}$ may be a major environmental factor affecting the genetic variation of PIUE under Fe-deficient conditions in the development of barley cultivars.

In this study, PIUE was determined in a central part of the newly developed leaf because young leaves are most affected by Fe-deficiency and the position inducing the long-term acclimation mechanisms to Fe-deficiency [13]. Therefore, it was necessary to confirm whether the analysis of local PIUE in young leaves could explain the differences in total growth under Fe-deficiency in barley varieties. For this purpose, the shoot and root biomass of the 18 representative barley varieties was compared with their relative PIUE value as the ratio of Fe-deficient to Fe-sufficient conditions. There was a significant positive correlation between relative PIUE and the relative biomass of the shoot (Figure 6A) or root (Figure 6B). This result is reasonable because the upper young leaves have a significant role as the plant canopy, which is the most favorable position for $\mathrm{CO}_{2}$ assimilation and plant growth [30]. Therefore, we confirmed that the analytical method of PIUE is reliable and not only shows Fe-use efficiency in the analyzed young leaf but also reflects the growth of the whole plant under Fe-deficient conditions. 


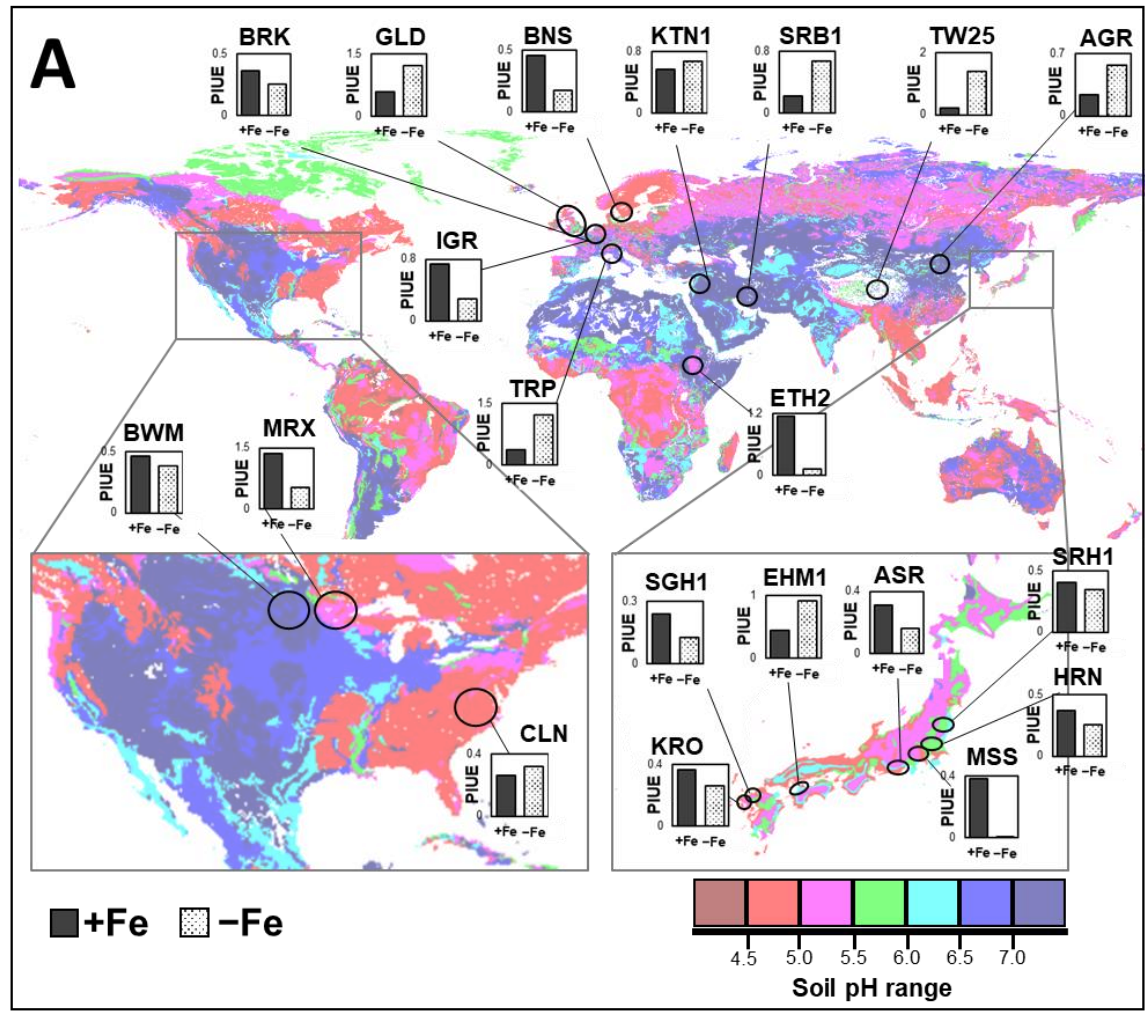

B

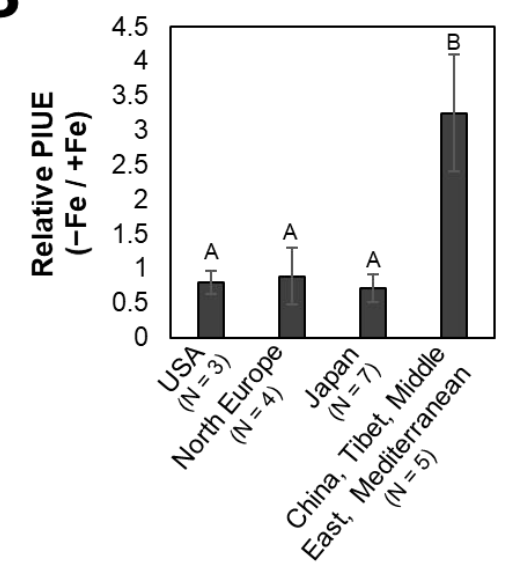

C

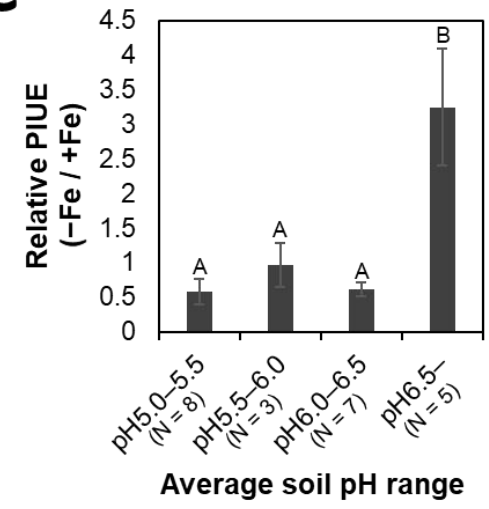

Figure 5. Relationship between soil $\mathrm{pH}$ and global distribution of barley varieties with a different calculated photosynthetic Fe-use efficiency (PIUE). The distribution of 20 barley varieties on the world soil $\mathrm{pH}$ map (A). The inserted small bar graphs in (A) represent the absolute PIUE (Figure 4A) of each variety in Fe-sufficient $(+\mathrm{Fe})$ and Fe-deficient $(-\mathrm{Fe})$ conditions. As shown in the color charts below the map, areas filled with dark blue indicate alkaline and with dark red indicate acidic subsoil $\mathrm{pH}$ (30-100 cm depth). The collection site or production site of each barley variety was placed on the map at its original location of cultivation. Comparison of relative PIUE as the ratio of Fe-deficiency to Fe-sufficiency classified by the different geographical areas among 20 barley cultivars (B) and by the soil $\mathrm{pH}$ of 23 barley varieties including wild barley H. vulgare spontaneum and H. murinum (C). The significant differences among the data in (B) or $(\mathbf{C})$ were tested using the Tukey's multiple tests $(p<0.05$, same capital letters indicate no significant difference). The global soil $\mathrm{pH}$ map was created by a software Harmonized World Soil Database (HWSD) viewer (FAO/IIASA/ISRIC/ISSCAS/JRC, 2012. Harmonized World Soil Database (version 1.2). FAO, Rome, Italy and IIASA, Luxemburg, Austria) [29]. 

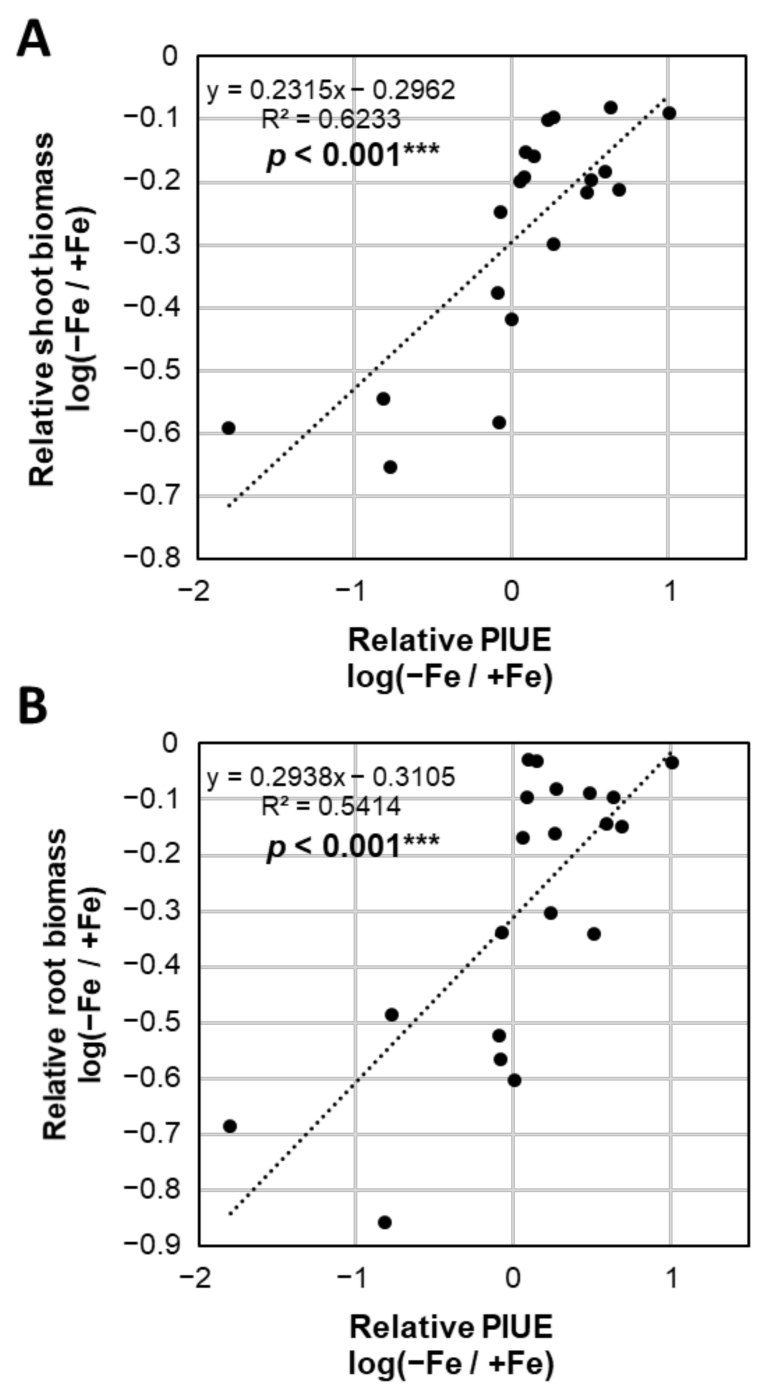

Figure 6. Correlation between biomass and photosynthetic Fe-use efficiency (PIUE) among barley varieties. Relative shoot biomass (A) and root biomass (B) as the ratio of Fe-deficiency to Fe-sufficiency. Plants in the vegetative growth phase were grown in hydroponic solution with or without Fe for 16 days. These variables (Supplementary Table S2) were converted to logarithms to fit the regression line. Significance of differences in Pearson's correlation coefficient between relative PIUE and relative shoot biomass was determined using the Student's $t$ test $\left({ }^{* *} p<0.001\right)$.

\subsection{Photosynthetic Properties Associated with the Relative PIUE Value in Barley Varieties}

To estimate which photosynthetic processes are responsible for the differences in PIUE under Fe-deficient condition, we compared various indexes related to photosynthesis: the maximal quantum yield of PSII photochemistry (Fv/Fm) as an index for PSII integrity, the quantum yield of PSII photochemistry $\left(\mathrm{Fv}^{\prime} / \mathrm{Fm}^{\prime}\right)$, photochemical quenching (qP), and effective quantum yield of electron transport ( $\varphi$ PSII) for functions of photosynthetic electron transport, non-photochemical quenching (qN and NPQ) for thermal dissipation, stomatal conductance for $\mathrm{CO}_{2}$ gas diffusion $\left(\mathrm{g}_{\mathrm{s}}\right)$, and $\varphi \mathrm{CO}_{2}$ for the efficiency of $\mathrm{CO}_{2}$ assimilation. All analyses were performed simultaneously with the measurement of $\mathrm{CO}_{2}$ assimilation analysis in the same plants used for Figures 3-6. The newly developed leaves of 18 barley varieties (see the caption in Supplementary Table S2) were analyzed at a moderate light strength of $500 \mu \mathrm{mol}$ photons $\mathrm{m}^{-2} \mathrm{~s}^{-1}$. We conducted correlation analysis and principal component analysis (PCA) using the various photosynthetic data (Supplementary Table S2 and Figure S4). The datasets for these multivariate analyses consisted of log-transformed relative values $(-\mathrm{Fe} /+\mathrm{Fe})$ of photosynthetic parameters and other measured values (Supplementary Table S2). 
The results of the correlation analysis showed that PIUE was positively correlated with the value of $\mathrm{qP}(\mathrm{r}=0.843)$, followed by the other parameters related to the electron transport within PSII, such as $\varphi$ PSII $(\mathrm{r}=0.835)$ and $\mathrm{Fv}^{\prime} / \mathrm{Fm}^{\prime}(\mathrm{r}=0.739)$ (Figure 7A). On the other hand, $\mathrm{g}_{\mathrm{s}}, \mathrm{Fv} / \mathrm{Fm}$, and $\varphi \mathrm{CO}_{2}$ had a lower correlation $(\mathrm{r}=0.727,0.685$, and 0.548 , respectively) with PIUE than the above parameters (Figure 7A). NPQ had little or no correlation with PIUE (Figure 7A). Respiratory activity (Resp) was maintained in all cultivars under Fe-deficiency and thus showed no relationship to the pattern of PIUE changes among barley varieties. SPAD value and leaf Fe content are commonly used as indicators of Fe-deficiency-tolerance, but their association with PIUE within barley cultivars was lower than that of the parameters related to the electron transport. A heatmap was drawn to visualize the correlation matrix between variables related to photosynthesis (Figure 7B), confirming that $\mathrm{qP}$ and PIUE were most associated with each other as they were in the same branch of the hierarchical clustering.

From PCA analysis, the first principal component (PC1) and second principal component (PC2) were used in biplots (Figure 8) because the sum of the contribution of PC1 and PC2 was sufficiently large to explain the variance (63\% and $18 \%$, respectively). The loading vector of PIUE showed a direction similar to that of qP, forming the same cluster. However, $\mathrm{Fv} / \mathrm{Fm}, \mathrm{Fv}^{\prime} / \mathrm{Fm},{ }^{\prime} \varphi \mathrm{PSII}$, and $\varphi \mathrm{CO}_{2}$ formed a different cluster, which was slightly separated from PIUE and $\mathrm{qP}$ (Figure 8). NPQ and $\mathrm{qN}$ showed different directional vectors from the PIUE. Leaf Fe concentrations were entirely unrelated to all photosynthesis-related parameters, confirming that leaf Fe content is not an indicator of photosynthesis within barley varieties (Figure 3). These results suggest that different responses of PIUE to Fe-deficiency within barley varieties were most related to the electron transfer system represented by qP. The degree of PSII integrity, photoprotective thermal dissipation, and carbon assimilation enzymes in stroma could not be the primary factors associated with PIUE because of the low relevance of $\mathrm{Fv} / \mathrm{Fm}, \mathrm{NPQ}$, and $\varphi \mathrm{CO}_{2}$ to PIUE. 

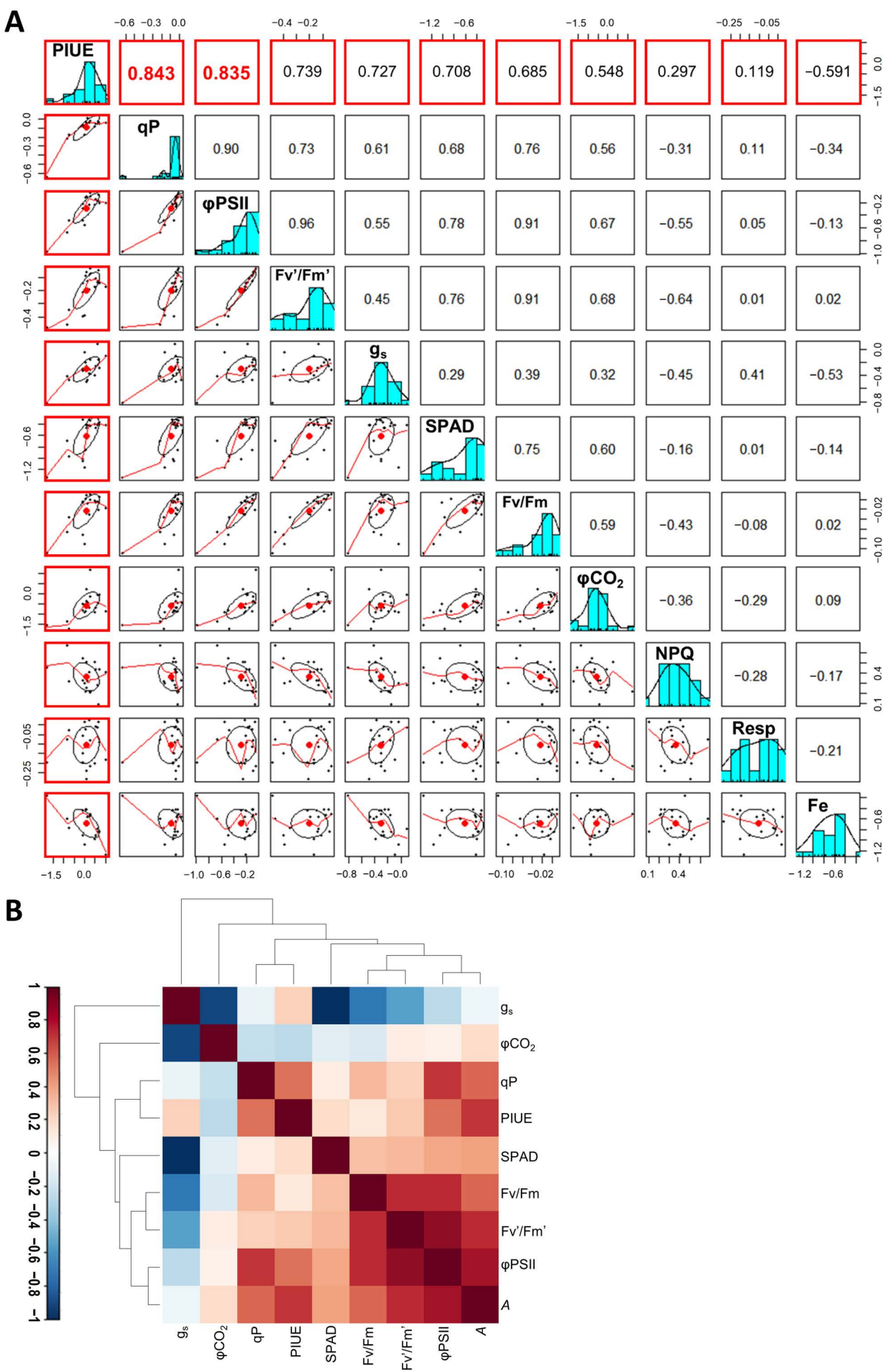

Figure 7. Correlation analysis of relative PIUE and relative variables among 18 barley varieties. (A) Scatter plot matrices among variables obtained in this study. These variables were the relative values as the ratio of Fe-deficiency to Fe-sufficiency and they were converted to logarithms. The values in the red square in the top row are Pearson correlation coefficients ( $r$ ) as relative PIUE vs. relative $\mathrm{qP}$, relative $\varphi \mathrm{PSII}$, relative $\mathrm{Fv}^{\prime} / \mathrm{Fm}^{\prime}$, relative stomatal conductance $\left(\mathrm{g}_{\mathrm{s}}\right)$, relative SPAD value, relative $\mathrm{Fv} / \mathrm{Fm}$, relative $\varphi \mathrm{CO}_{2}$, relative respiration rate (Resp), relative NPQ, and relative leaf $\mathrm{Fe}$ concentration $(\mathrm{Fe})$. The original data used for the analysis are presented in Supplementary Table S2. (B) Heatmap colored correlation matrix for 10 variables in the dataset of 18 barley varieties. Abbreviations: stomatal conductance $\left(\mathrm{g}_{\mathrm{s}}\right)$, quantum yield of carbon assimilation $\left(\varphi \mathrm{CO}_{2}\right)$, photochemical quenching coefficient (qP), photosynthetic Fe-use efficiency (PIUE), chlorophyll index (SPAD), maximal quantum yield of PSII photochemistry (Fv/Fm), quantum yield of PSII photochemistry $\left(\mathrm{Fv}^{\prime} / \mathrm{Fm}^{\prime}\right)$, effective quantum yield of electron transport in the light-acclimated state ( $\varphi$ PSII), net $\mathrm{CO}_{2}$ assimilation rate $(A)$. 


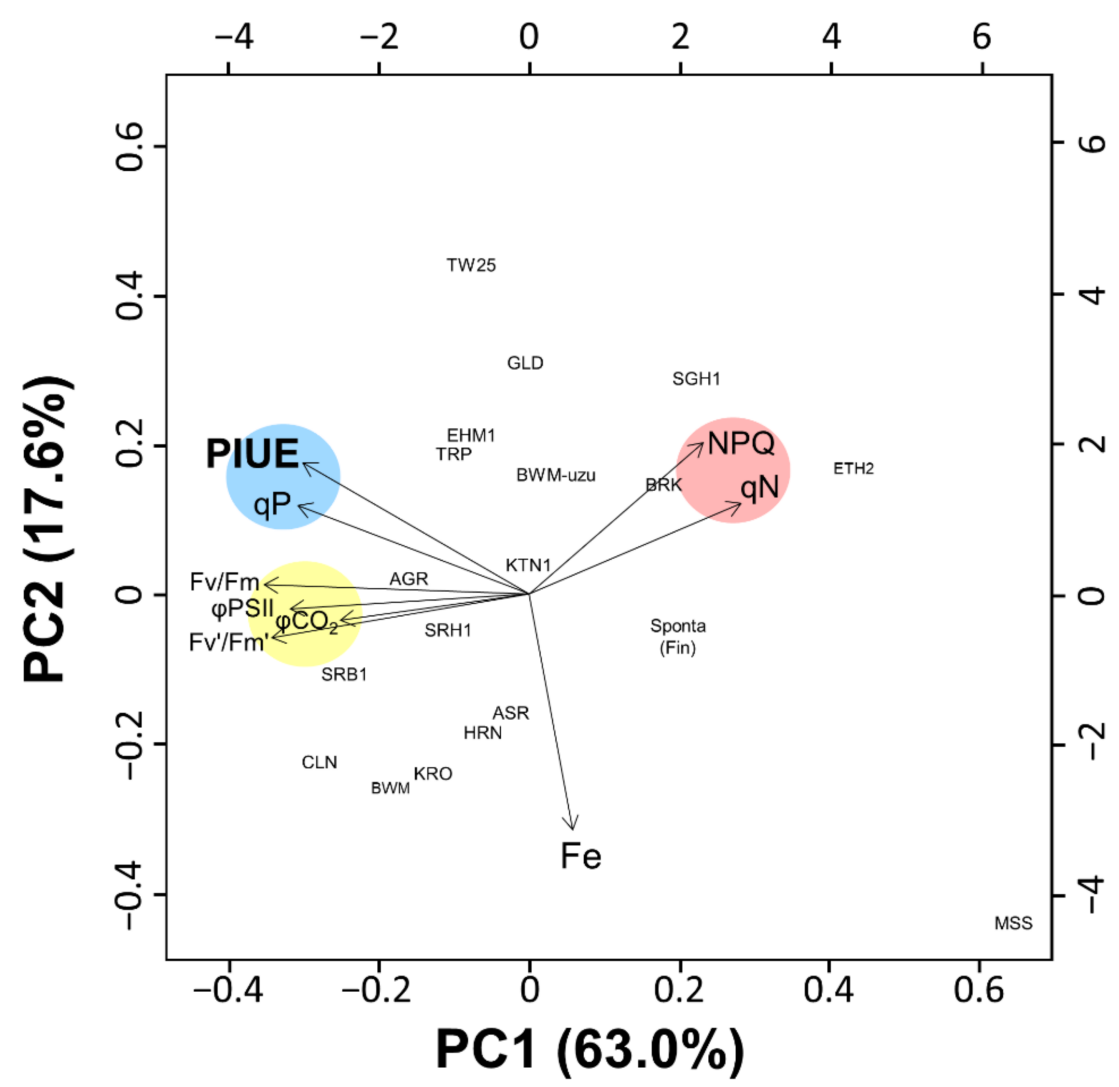

Figure 8. Principle component analysis (PCA) for nine variables in the dataset of 18 barley varieties. Blue, yellow, and red indicate clusters of photosynthetic Fe-use efficiency (PIUE)-related indices (PIUE and qP), electron transport-related indices ( $\mathrm{Fv} / \mathrm{Fm}, \mathrm{Fv}^{\prime} / \mathrm{Fm}^{\prime}, \varphi \mathrm{PSII}$, and $\left.\varphi \mathrm{CO}_{2}\right)$, and nonphotochemical quenching (qN and NPQ). Proportion of variances for PC1 and PC2 are shown in parentheses and in Supplementary Figure S5A. Loading of each variables is shown in Supplementary Figure S5B. Dataset of the logarithmic relative value $[\log (-\mathrm{Fe} /+\mathrm{Fe})]$ of variables related to photosynthesis are listed in Supplementary Table S2. Abbreviations of plant variety names are summarized below: 'Ehime Hadaka 1' (EHM1), 'Shiro Hadaka 1' (SRH1), 'Kairyo Ogara' (KRO), 'Haruna Nijo' (HRN), 'Akashinriki' (ASR), 'Saga Hadaka 1' (SGH1), 'Musashinomugi' (MSS), 'Colonial' (CLN), 'Bowman' (BWM), 'Bowman near-isogenic line uzu1.a' (BWM-uzu), 'Golden Promise' (GLD), 'Tripoli' (TRP), 'Sarab 1' (SRB1), 'Katana 1' (KTN1), 'Tibet White 25' (TW25), 'Ethiopia 2' (ETH2), 'Agriochriton' (AGR), 'Spontaneum' originated from Finland (Sponta-Fin).

\section{Discussion}

\subsection{PIUE, as a New Indicator that Defines Photosynthetic Fe-Use Efficiency}

In this study, we introduced a novel indicator, PIUE, to differentiate Fe economy during photosynthesis under Fe-deficient conditions. This attempt successfully characterized the Fe-use efficiencies in photosynthesis of $H$. vulgare varieties (Figures 4A and 5A). As far as we are aware, this is the first study assessing the photosynthetic Fe-use efficiency as a quantitative trait. Interestingly, PIUE was associated with $\mathrm{qP}$ when compared among barley varieties (Figures 7 and 8 ). The $\mathrm{qP}$ is literally the index of the ratio of energy quenched for photosynthesis [31] and largely reflects the redox state of $\mathrm{Q}_{\mathrm{A}}$ and downstream of PSII, including the PSI and Calvin cycles [31-33]. In the present study, PSII integrity, as indicated by Fv/Fm, was maintained in almost all barley varieties (Supplementary Table S2). Stomatal conductance and $\varphi \mathrm{CO}_{2}$, which reflect the activity of $\mathrm{CO}_{2}$ diffusion and Calvin cycle, showed a relatively low correlation with PIUE (Figure 7). Therefore, the reason for the difference in $\mathrm{qP}$ among barley varieties appears to be restricted downstream of PSII, such as in cyt $b_{6} f$ and PSI (Figure 9A). Because cyt $b_{6} f$ and PSI are the most Fe-requiring photosynthetic apparatus and the primary sufferer of Fe-deficiency in plants [1,3,5], the postulation that the key mechanism for increased PIUE under Fe-deficiency to exist downstream of PSII seems reasonable. 
A

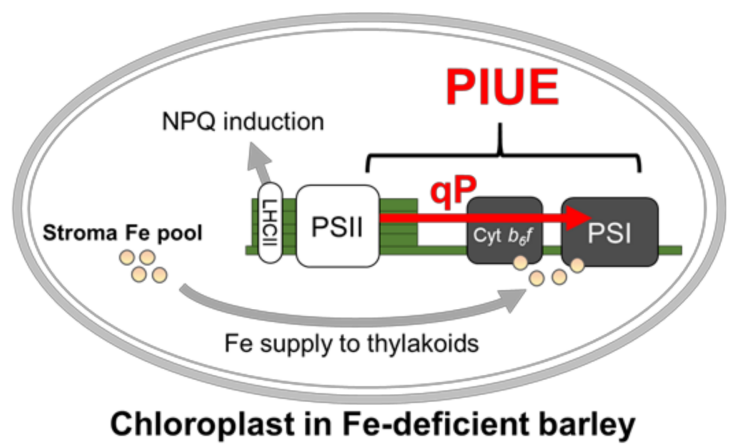

B

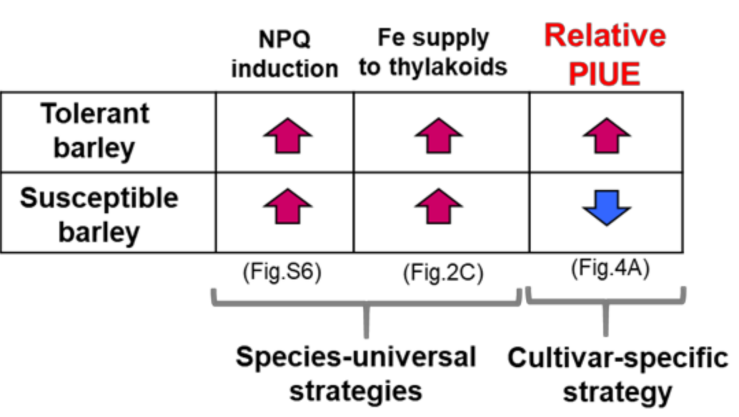

Figure 9. Model of adaptive mechanisms in chloroplasts of Fe-deficient barley. (A) Chloroplasts in Fe-deficient barley have at least three different mechanisms to adapt/acclimate to Fe-deficiency. High NPQ induction to protect from photoinhibition [13] and preferential Fe supply to the thylakoid membranes [17] are commonly observed in barley varieties grown under Fe-deficiency as fundamental acclimation mechanisms. Induction of high PIUE (the current study) was observed only in the barley varieties with Fe-deficiency-tolerance, which generally originated from regions covered with alkaline soils. (B) Relationship between Fe-deficiency-tolerance and the three adaptive mechanisms in chloroplasts. Red uparrows and blue down-arrows indicate an increase and decrease (or non-induction) of each mechanism under Fe-deficiency. The universality of each mechanism within $H$. vulgare species is shown below the table. The data to reach this conclusion are shown in parentheses.

\subsection{Possible Mechanisms that Affect PIUE}

There was no difference in Fe content on thylakoid membranes between barley varieties in this study (Figure 2C). Therefore, the reorganization of thylakoid proteins and optimization of Fe distribution to various Fe-containing proteins may also be important to increase or maintain PIUE under Fe-deficient conditions. Since cyt $b_{6} f$ and PSI are the complexes that require the most Fe in plant cells $[1,3,5]$ and are highly related to the $\mathrm{qP}$, there are possibilities that some of the Fe-transport/delivery pathways to these complexes may be involved in the efficiency of Fe-use in barley. A significant decrease of qP without alteration of the PSII complex has been reported in the mutants lacking HCF101 and APO1, the [4Fe-4S] cluster delivering proteins for PSI [31,34]. Similarly, CRR2, CRR6, PGR3, and PGR5 proteins for the cyclic electron transport influenced the $\mathrm{qP}$ and optimized the electron transport around cyt $b_{6} f$ and PSI [35-37]. It is reasonable to speculate that related pathways may contribute to the Fe-use efficiency in Fe-deficient barley.

The increase in accumulation of other transition metals such as $\mathrm{Mn}$ and $\mathrm{Cu}$ in leaves under Fe-deficiency is a long-known phenomenon [38]. We have also previously investigated the increased accumulation of various elements in Fe-deficient barley [16]. In this study, among the barley varieties, we found a marked increase in Mn accumulation in Fe-deficient leaves of the susceptible varieties, MSS, ETH2, SGH1, and Sponta-Fin (Supplementary Table S2). Excess Mn is also known to decrease PSI content [39]. In Arabidopsis, vacuolar Mn transporter MTP8 confers the tolerance to Fe-deficiency chlorosis by preventing interference of $\mathrm{Mn}$ in Fe acquisition [40]. Although it is unclear whether the excess Mn accumulation found in the Fe-deficiency-susceptible varieties is the cause or the consequence of the severe Fe-deficiency symptoms, excess Mn could reduce the Fe-use efficiency in chloroplasts. In addition to the Fe distribution mechanism in the chloroplast, the optimizing mechanisms of balance between Fe and other elements will need to be considered.

\subsection{Association of PIUE with Other Fe-Deficiency Acclimation Mechanisms Previously Found in Barley}

The increase in NPQ under Fe-deficient condition has been found in Fe-deficient barley by comparing photosynthetic function between barley and rice [13]. The elevated NPQ, 
namely thermal dissipation of light energy, is the reason why barley is less susceptible to photo-oxidative stress under Fe-deficiency than rice. The critical factor in this mechanism has been identified as isoforms of the HvLhcb1 $[13,18]$. This study confirmed that all barley varieties tested here significantly increased NPQ under Fe-deficient condition (Supplementary Figure S6A,B). As the NPQ induction is a primary photoprotective mechanism for PSII, almost all barley cultivars indeed maintain high Fv / Fm (0.7-0.8) under Fe-deficient conditions (Supplementary Table S2). This property is entirely different from rice and other Fe-deficiency-susceptible plants, where Fe-deficiency damages PSII. Thus, it becomes clear that the NPQ induction to protect PSII is a universal (fundamental) mechanism among barley varieties (Figure 9B).

Like NPQ induction, an increase in Fe supply to thylakoid membranes was observed in all analyzed barley varieties with different Fe-deficiency-tolerances (Figure 2C). This observation also suggests that the preferential supply of Fe to thylakoid membranes appear to be universal strategies to cope with Fe-deficiency in $H$. vulgare species (Figure 9B). Because of this universality, both NPQ and Fe were not correlated with PIUE (Figures 7A and 8). Therefore, these two universal mechanisms may be independent of the mechanism of PIUE induction under Fe-deficiency within $H$. vulgare species (Figure 9B). Comparisons between barley varieties with different values for PIUE could help elucidate the unknown Fe-deficiency adaptation mechanism to save Fe in chloroplasts, which is not universal within barley varieties.

Of note, however, rice and Arabidopsis could not induce the light-harvesting complex II (LHCII)-mediated NPQ under Fe-deficiency [3,13], suggesting that the photoprotective mechanism is not universal in the plant kingdom. Similarly, sorghum shows no sign to increase Fe in thylakoid membranes under Fe-deficiency [17]. Therefore, it is also evident that this characteristic adaptive mechanism commonly found among barley varieties is the key process in the greater tolerance of Fe-deficiency than in other plant species. In other words, cooperation with this species-specific (NPQ-induction and preferential Fe supply into thylakoids) and the varieties-specific mechanism (PIUE induction) would increase the total Fe-deficient-tolerance level in plants.

\subsection{New Insights on Barley Cultivation in Respect of Fe Nutrition}

Recent progress in genome analysis of barley has revealed deep links between geographic distribution and genetic diversity in this species [41]. Assuming that the genetic diversity of PIUE changes depending on soil $\mathrm{pH}$, it is possible to explain the current global distribution of barley varieties with different PIUE changes (Figure 5). Among the barley cultivars used in this study, six varieties with increased PIUE (TW25, TRP, SRB1, AGR, KTN1, and EHM1) originated from regions of alkaline soil (average soil pH above 6.5) or relatively high $\mathrm{pH}$ compared to the surrounding area (Figure 5A).

Areas with an average soil $\mathrm{pH}$ greater than 6.3 contain a wide range of alkaline soils because the actual soil $\mathrm{pH}$ is heterogeneous, as shown in Supplementary Table S1 (the column "Soil $\mathrm{pH}$ range at origin"). In aerated soils like farmlands for barley cultivation, the solubility of Fe decreases by a factor of 1000 for each unit increase in $\mathrm{pH}$ [7]. Therefore, barley grown in these areas is at high risk of low Fe availability. As we have reported [42], even a small change in $\mathrm{pH}$ significantly impacted the elongation of barley roots, indicating that such a slight increase of soil $\mathrm{pH}$ could alter the energy metabolism. In the case of Ambrosia artemisiifolia, $\mathrm{pH} 7$ is a serious environment, inhibiting the formation of flowers and pollen and delaying their growth [43]. Therefore, plants grown in an area with an average soil $\mathrm{pH}$ exceeding 6.5 must have a flexible mechanism to acclimate to Fe-deficiency to obtain sufficient yields. In this context, because the increase in PIUE would be a desirable trait for cultivation in alkaline soils, it is likely that these physiological traits have been inadvertently selected for in these regions during the long history of barley cultivation.

Conversely, varieties with a PIUE decreased by Fe-deficiency (MSS, BNS, IGR, SpontaFin, and ETH2) originated from acidic soil regions (Figure 5A). In such acidic soil environments, plants have almost no opportunity to encounter Fe-deficiency, but rather, stress 
from excess Fe will occur in these plants. Thus, unlike the case in alkaline soils, the ability to induce high PIUE provides no profit in obtaining high yields in acidic soil environments. Therefore, it is conceivable that part of the barley varieties adapted to acidic soil environments lost the ability, or the environment did not provide selective pressure to obtain the ability to induce high PIUE under Fe-deficiency.

Two varieties, CLN and GLD, did not match the above scenarios. Both cultivars increased their PIUE by Fe-deficiency despite growing in acidic soil (Figure 5). CLN was produced in 1938 in the USA by crossing two varieties, 'Davidson' and 'Sunrise'. Of these, 'Sunrise' was selected from the Japanese semi-dwarf variety 'Nakano Wase'. GLD was originally a dwarf mutant created in 1967 by gamma-ray irradiation of 'Maythorpe', a hybrid of the Danish 'Maja' and British 'Goldthorpe'. Both CLN and GLD have a dwarf mutation in their genome. However, there was no evident correlation between PIUE and dwarf morphology in barley (Appendix A, Figure A1). Therefore, it is more plausible to consider that these "new varieties" are no longer related to the soil $\mathrm{pH}$ of the current growth area because of the complex breeding process in the 20th century.

\subsection{The Origin of the Trait of PIUE Increase}

The question is raised as to when barley obtained this property of PIUE induction in response to Fe-deficiency. Wild barley, H. vulgare spontaneum, an ancestral species of cultured barley, is currently distributed globally. In this study, we found that the spontaneum originating from Iran (average soil $\mathrm{pH}$ above 7.0) had a higher PIUE under Fedeficiency than that from Finland (average soil $\mathrm{pH}<5.5$ ) (Figure 4A). Furthermore, another wild-barley, Hordeum murinum, originating from Spain (average soil pH $~ 7.0$ ) and closely related to Hordeum vulgare, has the highest absolute PIUE among plants used in this study (Figure 4A). These results suggest that the diversity of PIUE within the Hordeum species may exist before cultivation. Afterward, the beneficial genes linked to PIUE induction under Fe-deficiency would be integrated through human selection, resulting in the present Fe-efficient barley varieties. To elucidate this, it would be worth investigating the PIUE in various plant species. The relationship between PIUE and the adaptation of plants to Fe-deficiency will be a subject of future studies.

\subsection{C4 Photosynthesis Is Disadvantageous in PIUE Increase under Fe Deficient Conditions}

PNUE in the C4 photosynthetic plant is generally greater than that in the C3 plant [24]. In addition, C4 plants are tolerant to drought stress [44] and have higher photosynthetic wateruse efficiency (PWUE) than C3 plants [45]. However, unlike PNUE and PWUE, our results clearly showed that the average PIUE value collected from sorghum varieties (which have C4 photosynthesis) was significantly decreased by Fe-deficiency (Figure 4C). This result suggests that $\mathrm{C} 4$ photosynthesis is a disadvantage in acclimatizing to Fe-deficiency (Figure $4 \mathrm{~B}, \mathrm{C}$ ).

Indeed, $\mathrm{C} 4$ plants require a larger amount of $\mathrm{Fe}$ in the vascular bundle sheath cells that accumulate PSI complexes more than C3 plants [46]. Our previous studies demonstrated that sorghum has a lower ability for Fe distribution to the thylakoid membranes under Fe-deficient conditions than barley [17]. Only one sorghum variety, ' $\# 100$ ', seemed to maintain the PIUE under Fe-deficient conditions. It may be worthwhile to study whether there is an optimizing mechanism for PIUE in sorghum varieties.

\subsection{The Future Application of PIUE}

Fe takes various chemical forms in vivo and it is therefore difficult to quantitatively identify the precise positions and chemical structures of trace amounts of Fe. This difficulty has made it challenging to perform comprehensive screening of plants with different Fe-saving systems in chloroplasts. In this regard, PIUE has an advantage in that it can be analyzed in any leaf position in any plant species (Figure 4) in both laboratory and field environments. Such applications of PIUE will further deepen our knowledge of the properties of Fe-economy in chloroplasts. 
Quantitative trait loci (QTLs) analyses and genome-wide association studies (GWAS) have been performed using indices related to resource-use efficiencies. Recently, multiple QTLs or genes related to such efficiencies in photosynthesis have been identified [47,48]. The classification of plants by relative PIUE $(-\mathrm{Fe} /+\mathrm{Fe})$ can produce apparently different results compared to the traditional indices, SPAD, and Fe content (Figure 7). We expect that PIUE may become a novel index as a quantitative trait for such genetic analyses. For this purpose, $\mathrm{F}_{2}$ crossing lines from several barley varieties with different PIUE responses are now under development.

In summary, photosynthetic Fe-use efficiency can be a key trait in maintaining growth under Fe-deficiency within Hordeum species (Figure 6). The difference in Fe-deficiencytolerance within $H$. vulgare species is associated with its ability to increase PIUE under Fe-deficiency. It is likely that the mechanism of the PIUE increase in Fe-deficient barley is related to optimizing the electron flow downstream of PSII. Further analyses of Fe partitioning and the compositional changes of thylakoid proteins will be needed to clarify this assumption. With the application of PIUE, it is expected that molecular mechanisms will be identified to improve Fe-economy under Fe-deficient conditions.

\section{Materials and Methods}

\subsection{Plant Materials and Growth Conditions}

Varieties of barley (Hordeum vulgare L. 'Ehime Hadaka 1' (EHM1), 'Shiro Hadaka 1' (SRH1), 'Kairyo Ogara' (KRO), 'Haruna Nijo' (HRN), 'Akashinriki' (ASR), 'Saga Hadaka 1' (SGH1), 'Musashinomugi' (MSS), 'Colonial' (CLN), 'Bowman' (BWM), 'Bowman nearisogenic line uzu1.a' (BWM-uzu), 'Bonus (BNS), 'Igri' (IGR), 'Barke' (BRK), 'Morex' (MRX), 'Golden Promise' (GLD), 'Tripoli' (TRP), 'Sarab 1' (SRB1), 'Katana 1' (KTN1), 'Tibet White 25' (TW25), 'Ethiopia 2' (ETH2), 'Agriochriton' (AGR), 'Spontaneum' originated from Iran (Sponta-Iran), 'Spontaneum' originated from Finland (Sponta-Fin),' and Hordeum murinum

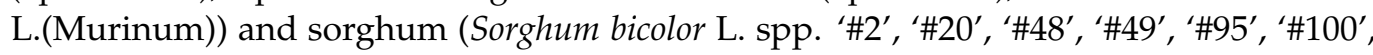
and ' $\# 168$ ') used in this study are summarized in Supplementary Table S1. Among them, 15 barley varieties were kindly provided by Professor Kazuhiro Satoh (Barley Germplasm Center, Okayama University, Japan) and the other eight barley accessions, including wild species of barley, were kindly provided by the Nordic Genetic Resource Center (https://www.nordgen.org/en/plants/plant-material/). 'BWM-uzu' was also kindly provided by the National Small Grains Collection, at the United States Department of Agriculture (https:/ / www.ars-grin.gov/npgs/collections.html). All sorghum varieties were provided by EARTHNOTE Co., Ltd., Tokushima, Japan. Seeds of barley and sorghum were germinated on moist filter paper after water absorption at $4{ }^{\circ} \mathrm{C}$ for several days.

The seedlings were then grown hydroponically in a growth chamber at $24{ }^{\circ} \mathrm{C}$. The growth light intensity was set at $200-300 \mu \mathrm{mol}$ photons $\mathrm{m}^{-2} \mathrm{~s}^{-1}$ under $14 \mathrm{~h}$ light $/ 10 \mathrm{~h}$ dark cycles. After germination, pre-culture was carried out until the seed nutrients were completely consumed. Pre-culture was conducted with a half-strength hydroponic solution containing $30 \mu \mathrm{M}$ Fe-EDTA. After 11-12 days of the pre-culture, the length of the second leaf exceeded that of the first leaf, then the plants were transferred to the hydroponic solution $\left(0.7 \mathrm{mM} \mathrm{K}_{2} \mathrm{SO}_{4}, 0.1 \mathrm{mM} \mathrm{KCl}, 0.1 \mathrm{mM} \mathrm{KH}_{2} \mathrm{PO}_{4}, 2 \mathrm{mM} \mathrm{Ca}\left(\mathrm{NO}_{3}\right)_{2}, 0.5 \mathrm{mM} \mathrm{MgSO}_{4}, 10 \mu \mathrm{M}\right.$ $\mathrm{H}_{3} \mathrm{BO}_{3}, 0.5 \mu \mathrm{M} \mathrm{MnSO}_{4}, 0.5 \mu \mathrm{M} \mathrm{ZnSO}_{4}$, and $0.2 \mu \mathrm{M} \mathrm{CuSO}_{4}$ and $\left.\left(\mathrm{NH}_{4}\right) 6 \mathrm{Mo}_{7} \mathrm{O}_{24}\right)$ with $30 \mu \mathrm{M}$ Fe-EDTA for barley and $100 \mu \mathrm{M}$ Fe-EDTA for sorghum to provide Fe-sufficient conditions. No Fe was added after pre-culture to induce Fe-deficiency for all barley varieties, except for the experiment in Figure 2. To prepare Fe-deficient sorghum varieties, 3-10 $\mu \mathrm{M}$ of Fe-EDTA was added to maintain their growth at a SPAD level of approximately 15.

For the experiments in Figure 2, Fe concentrations of the hydroponic solution for the Fe-deficient treatment were adjusted from 0 to $1 \mu \mathrm{M}$ for the Fe-efficient varieties (EHM1 and SRB1) and from 2 to $3 \mu \mathrm{M}$ for the Fe-inefficient varieties (MSS and ETH2) to standardize the chlorophyll content across all the varieties analyzed. Since the current study focused on the photosynthetic acclimation to Fe-deficiency in young developed leaves [13], the mechanism is fully induced after 16 days of Fe-deficiency. Therefore, the Fe treatment was conducted 
for 16-20 days after the pre-culture in the case of barley and for 10-14 days in the case of sorghum. The nutrient solutions were renewed every $2-4$ days. For varieties suffering from excessive heavy metal stress under Fe-deficient conditions, the concentrations in the hydroponic solution of $\mathrm{Mn}, \mathrm{Zn}$, and $\mathrm{Cu}$ were reduced to $0.1,0.1$, and $0.05 \mu \mathrm{M}$, respectively. The details are described in Supplementary Table S1.

\subsection{Isolation of Thylakoid Membranes}

Young, fully expanded chlorotic leaves and corresponding control leaves were analyzed after 2-3 weeks when the chlorosis symptoms remained constant. Thylakoid membrane extraction was simplified as described previously [49]. Reagents and the detailed procedures are presented in Appendix A (Methods A1). In brief, leaf strips were mildly homogenized with an isotonic solution and crude chloroplasts were collected in the flow-through of Miracloth (Merck, Burlington, MA, USA). Crude chloroplasts were ruptured by a hypotonic solution, and the thylakoid fraction was obtained. The thylakoid membrane was washed with EDTA solution [50].

\subsection{Measurement of Chlorophyll and Fe Content in Leaves}

The SPAD value (index of total chlorophyll content in a leaf area) of the central parts of the youngest, fully developed leaves (5th to 6th leaves for barley, 4th to 5th leaves for sorghum - the cotyledon was counted as the first leaf) was analyzed using SPAD502 (Minolta, Osaka, Japan). Chlorophylls were quantified after extraction with 80\% $(v / v)$ acetone [51].

Fe concentration was measured using an atomic absorption spectrometer (AA-6300, Shimadzu, Tokyo, Japan) coupled with a graphite furnace atomizer (GFA-EX7i, Shimadzu) after the digestion of leaf materials, as described previously [13]. To determine trace Fe in thylakoid membranes (Figure 2C), extremely clean reagents, instruments, and atmosphere were prepared. Digestion was performed with Teflon tubes (perfluoroalkoxy alkanes (PFA) sample test tube, T43-012, Matsuura-Seisakusho Co. Ltd., Tokushima, Japan), which release no Fe when heated with $\mathrm{HNO}_{3}$. All Teflon tubes and plastic tips with filters were soaked in diluted $\mathrm{HNO}_{3}$ before use. The bench was covered with a simple household greenhouse composed of steel pipes and a plastic cloth.

\subsection{Measurement of Photosynthesis}

Leaf gas exchange measurements were coupled with measurements of chlorophyll fluorescence using an open gas exchange system (LI-6400XT, LI-COR, Inc., Lincoln, NE, USA) with an integrated fluorescence chamber head (LI-6400-40 leaf chamber fluorometer; LI-COR, Inc.). Youngest, fully developed leaves (5th to 6th leaves for barley, 4th to 5th leaves for sorghum - the cotyledon was counted as the first leaf) were analyzed, and $\mathrm{CO}_{2}$ assimilation rate $\left(A: \mu \mathrm{mol} \mathrm{CO} \mathrm{m}^{-2} \mathrm{~s}^{-1}\right)$ and stomatal conductance $\left(\mathrm{g}_{\mathrm{s}}: \mathrm{mol} \mathrm{H}_{2} \mathrm{O} \mathrm{m}^{-2} \mathrm{~s}^{-1}\right)$ were measured at $500 \mu \mathrm{mol}$ photons $\mathrm{m}^{-2} \mathrm{~s}^{-1}$. Respiration rate (Resp: $\mu \mathrm{mol} \mathrm{CO} \mathrm{Cm}^{-2} \mathrm{~s}^{-1}$ ) was measured as the amount of $\mathrm{CO}_{2}$ released in darkness. Measurements were set as follows: block temperature $=24{ }^{\circ} \mathrm{C}$, reference $\mathrm{CO}_{2}$ concentration $=400 \mu \mathrm{mol} \mathrm{m}{ }^{-2} \mathrm{~s}^{-1}$, flow $=500 \mu \mathrm{mol} \mathrm{s}^{-1}$, and actinic light intensity $=500 \mu \mathrm{mol}$ photons $\mathrm{m}^{-2} \mathrm{~s}^{-1}$ (containing $10 \%$ of blue light). The quantum yield of carbon assimilation $\left(\varphi \mathrm{CO}_{2}\right)$ was calculated as (1):

$$
\varphi \mathrm{CO}_{2}=A_{\text {light }}-A_{\text {dark }} / I \alpha_{\text {leaf }},
$$

where $A_{\text {light }}$ and $A_{\text {dark }}$ are the $\mathrm{CO}_{2}$ assimilation rate in light and dark respectively, $I$ is the incident photon flux density, and $\alpha_{\text {leaf }}$ is the leaf absorptance.

Chlorophyll fluorescence analysis was performed for 18 barley varieties, as shown in Figure 7, simultaneously with gas exchange analysis using LI-6400XT and LI6400-40 (LI-COR, Inc.), as previously described [13]. In brief, the maximum level of fluorescence was determined after receiving a saturating pulse in a dark-adapted state (Fm) or in the light-acclimated state $\left(\mathrm{Fm}^{\prime}\right)$. The minimum fluorescence $(\mathrm{Fo})$ was measured using a sufficiently low intensity. After the steady-state level (Fs) of the actinic irradiance was 
measured, the actinic light was turned off, and Fo' (the minimum fluorescence level in the light-acclimated state) was determined with far-red light. Calculations were performed using the following parameters:

$$
\mathrm{Fv} / \mathrm{Fm}=(\mathrm{Fm}-\mathrm{Fo}) / \mathrm{Fm}
$$

where Fv/Fm is the maximal quantum yield of PSII photochemistry,

$$
\mathrm{Fv}^{\prime} / \mathrm{Fm}^{\prime}=\left(\mathrm{Fm}^{\prime}-\mathrm{Fo}^{\prime}\right) / \mathrm{Fm}^{\prime}
$$

where $\mathrm{Fv}^{\prime} / \mathrm{Fm}^{\prime}$ is the quantum yield of PSII photochemistry,

$$
\varphi \mathrm{PSII}=\left(\mathrm{Fm}^{\prime}-\mathrm{Fs}^{\prime}\right) / \mathrm{Fm}^{\prime}
$$

where $\varphi$ PSII is the effective quantum yield of electron transport in the light-acclimated state,

$$
\mathrm{qP}=\left(\mathrm{Fm}^{\prime}-\mathrm{Fs}\right) /\left(\mathrm{Fm}^{\prime}-\mathrm{Fo}^{\prime}\right)
$$

where $\mathrm{qP}$ is the photochemical quenching coefficient,

$$
\mathrm{qN}=\left(\mathrm{Fm}-\mathrm{Fm}^{\prime}\right) /\left(\mathrm{Fm}^{\prime}-\mathrm{Fo}^{\prime}\right)
$$

where $\mathrm{qN}$ is the non-photochemical quenching and

$$
\mathrm{NPQ}=\left(\mathrm{Fm}-\mathrm{Fm}^{\prime}\right) / \mathrm{Fm}^{\prime}
$$

where NPQ is also the non-photochemical quenching.

\subsection{Calculation of PIUE}

After the measurements of the $\mathrm{CO}_{2}$ assimilation rate $\left(\mu \mathrm{mol} \mathrm{CO} \mathrm{Cm}^{-2} \mathrm{~s}^{-1}\right)$, the central part of the analyzed leaf was cut out with a razor, washed with distilled water, and the area of the detached leaves was calculated using a scanning image based on the area value of the grid paper. The dry weight of the detached leaves was measured after overnight drying at $80^{\circ} \mathrm{C}$. The Fe concentration per leaf area ( $\mu \mathrm{mol}$ Fe per $\mathrm{m}^{2}$ leaf area) was calculated based on the dry weight (DW) per $\mathrm{m}^{2}$ (g leaf DW per $\mathrm{m}^{2}$ leaf area). Finally, PIUE ( $\mu \mathrm{mol} \mathrm{CO}_{2}$ $\mathrm{mol}^{-1} \mathrm{Fe} \mathrm{s}^{-1}$ ) was calculated as the $\mathrm{CO}_{2}$ assimilation rate divided by the Fe concentration per leaf area. To guarantee the reproducibility of PIUE analysis, a representative barley variety, 'Ehime Hadaka 1' (EHM1), was grown thrice to obtain three repetitive datasets.

\subsection{Statistical Data Analysis}

The log-transformed value of Fe-deficiency $(-\mathrm{Fe}) / \mathrm{Fe}$-sufficiency $(+\mathrm{Fe})$ of each index of chlorophyll fluorescence, stomatal conductance, $\mathrm{CO}_{2}$ assimilation rate, biomass, and leaf Fe concentration were used to evaluate the variation in the photosynthetic traits among 18 barley varieties grown under Fe-sufficient and Fe-deficient conditions (Supplementary Table S2). Clustering heatmap analysis, scatter plot matrices, and principal component analysis (PCA) were performed using $\mathrm{R}$ original packages, pairs.panels and corrplot, respectively ( $\mathrm{R}$ version 4.0.3).

Supplementary Materials: The following are available online at https:/ / www.mdpi.com/2223-7 747/10/2/234/s1, Figure S1: Fe-deficiency-tolerance among four representative barley varieties, Figure S2: Comparison of the Fe concentration of four representative barley varieties showing different tolerance of Fe-deficiency, Figure S3: Comparison of the Fe distribution of four representative barley varieties showing different tolerance of Fe-deficiency, Figure S4: Raw data of $\mathrm{CO}_{2}$ assimilation rate and leaf Fe concentration in the leaves of barley and sorghum, Figure S5: The proportion of variance and the loadings of individual variables in PCA analysis, Figure S6: Nonphotochemical quenching (NPQ) among barley in young developed leaves of plants grown under Fe-sufficient or Fe-deficient condition, Table S1: List of barley and sorghum varieties used in this study, Table S2: 
Absolute values and relative values (fold-change) of each parameter used for the correlation analysis and PCA analysis.

Author Contributions: Conceptualization and methodology, A.S. (Akihiro Saito) and K.H.; software and validation, A.S. (Akihiro Saito); formal analysis and investigation, S.S., D.I., Y.D., A.S. (Akira Sato), Y.W., J.H., Y.A. and T.M.; data curation, A.S. (Akihiro Saito); writing-original draft preparation, A.S. (Akihiro Saito); writing-review and editing, K.H. and T.O.; project administration, K.H. and A.S. (Akihiro Saito); funding acquisition, K.H. All authors have read and agreed to the published version of the manuscript.

Funding: This research was funded by EARTHNOTE Co., Ltd. granted to K.H.

Institutional Review Board Statement: Not applicable.

Informed Consent Statement: Not applicable.

Data Availability Statement: Data is contained within the article or supplementary material.

Acknowledgments: The authors thank Kazuhiro Satoh (Barley Germplasm Center, Okayama University, Japan), the Nordic Genetic Resource Center (NordGen), and the National Small Grains Collection (USDA, USA) for providing barley seeds. We also thank Junichi Yoneda and Tsuyoshi Tokunaga (EARTHNOTE Co., Ltd.) for providing the various sorghum varieties.

Conflicts of Interest: The funder EARTHNOTE Co., Ltd. had no role in the design of the study; in the collection, analyses, or interpretation of data; in the writing of the manuscript, or in the decision to publish the results. All authors declare no competing interests.

\section{Appendix A}
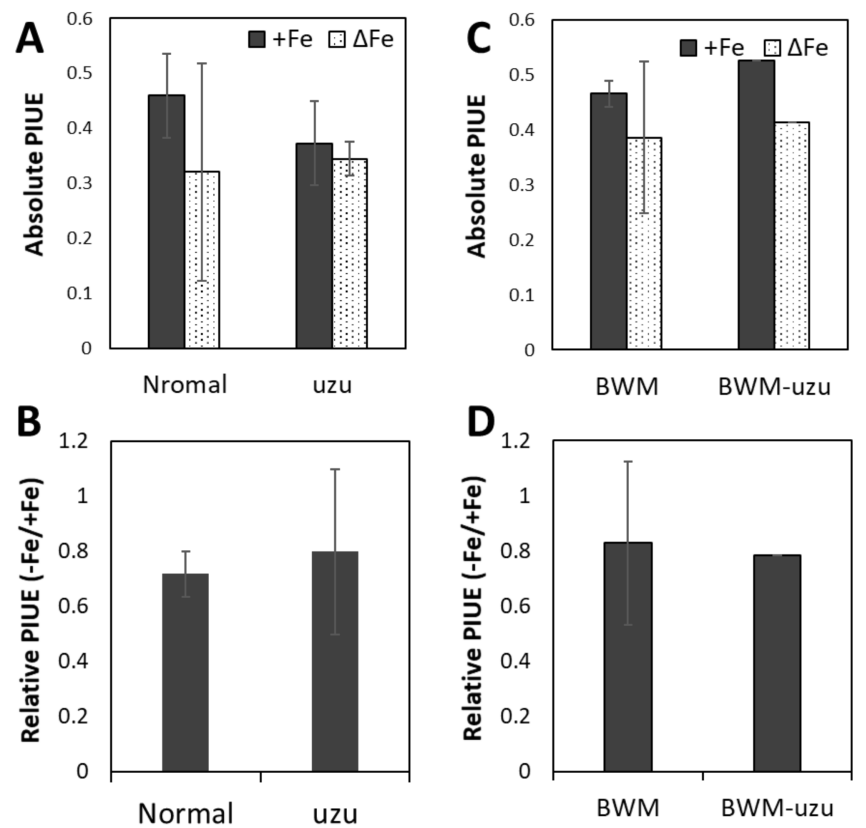

Figure A1. Photosynthetic Fe-use efficiency (PIUE) between $u z u$ semi-dwarf and normal Japanese barley varieties. Absolute PIUE (A) and relative PIUE (B) of normal and $u z u$ semi-dwarf Japanese barley varieties. For normal barley, the average value was obtained from the mean values of 'Shiro Hadaka 1' (SRH1), 'Kairyo Ogara' (KRO), and 'Haruna Nijo' (HRN). For uzu semi-dwarf barley, the average value was obtained from mean values of 'Ehime Hadaka 1' (EHM1), 'Akashinriki' (ASR), 'Saga Hadaka 1' (SGH1), 'Musashinomugi' (MSS), and 'Colonial' (CLN). Absolute PIUE (C) and relative PIUE (D) of 'Bowman' (BWM) and 'Bowman near-isogenic line uzu1.a' (BWM-uzu). Data represent means of triplicate determinations for BWM and one experiment for BWM-uzu.

Plant morphology has a significant impact on the efficiency of photosynthesis and nutrient utilization [52]. Barley semi-dwarfing (called " $u z u^{\prime \prime}$ ) is a phenotype that arises 
from a natural recessive mutation and is genetically inherited by many Japanese varieties. The causal gene of the mutation is the brassinosteroid receptor gene, HvBR1, demonstrating a phenotype of a deep leaf color and low plant height [53]. This semi-dwarf phenotype confers resistance to humidity and lodging [54] and may also affect nutrient-use efficiency [55]. Recently, it was reported that plant hormone brassinosteroids were involved in Fe homeostasis in rice [56]. Therefore, we expected a relationship between photosynthetic function and the $u z u$ phenotype under Fe-deficiency in barley.

However, we could not find any differences in PIUE between the normal and $u z u$ Japanese barley varieties (Figure A1A,B). For instance, EHM1 is one of the $u z u$-varieties that is highly tolerant to Fe-deficiency with increased PIUE, whereas MSS is an Fe-deficiencysusceptible $u z u$-variety with the lowest PIUE under Fe-deficient conditions. A similar result was obtained by comparing BWM and its near-isogenic line uzu1.a (BWM-uzu) (Figure A1C,D). Therefore, we concluded that the $u z u$-mutation has little or no impact on Fe-deficiency-tolerance and the PIUE increase.

\section{Methods A1: Isolation of Thylakoid Membranes}

Stock solutions:

- $\quad 250 \mathrm{mM}$ HEPES-KOH ( $\mathrm{pH} 7.6)$, stored at $4{ }^{\circ} \mathrm{C}$

- Antioxidant solution, stored at $-20^{\circ} \mathrm{C}$

$20 \mathrm{mM}$ ascorbate

20 mM EDTA-2Na

- $10 \times \mathrm{HM}$ buffer, stored at $4{ }^{\circ} \mathrm{C}$

$100 \mathrm{mM}$ HEPES-KOH (pH 7.6)

$50 \mathrm{mM} \mathrm{MgCl} 2 \cdot 6 \mathrm{H}_{2} \mathrm{O}$

- $\quad 10 \times$ EDTA washing buffer, stored at $4{ }^{\circ} \mathrm{C} 100 \mathrm{mM}$ HEPES-KOH (pH 7.6)

$50 \mathrm{mM}$ EDTA-2Na

Working solutions:

- Blending medium

$0.35 \mathrm{M}$ sucrose

25 mM HEPES-KOH (pH 7.6)

$2 \mathrm{mM}$ ascorbate

2 mM EDTA-2Na

- HM buffer

$10 \mathrm{mM}$ HEPES-KOH (pH 7.6)

$5 \mathrm{mM} \mathrm{MgCl}_{2}$

- $\quad$ EDTA washing buffer

$10 \mathrm{mM}$ HEPES-KOH (pH 7.6)

5 mM EDTA-2Na

Procedures:

All procedures were performed under ice-cold conditions with low-binding plastic tips and tubes.

(1) Leaf strips (2.5 g) were homogenized twice for $5 \mathrm{~s}$ each with $25 \mathrm{~mL}$ blending medium in $50 \mathrm{~mL}$ plastic tubes using a Physcotron homogenizer (MICROTEC Co., Ltd., Japan) set at $29,000 \mathrm{rpm}$.

(2) Homogenate was filtered with three-layered Miracloth (EMD Millipore Corp., Bedford, MA, USA).

(3) Crude chloroplasts were collected as pellets by centrifugation at $2500 \times \mathrm{g}$ at $4{ }^{\circ} \mathrm{C}$ for $10 \mathrm{~min}$.

(4) Green pellets were suspended in $10 \mathrm{~mL}$ of $\mathrm{HM}$ buffer and then incubated for $10 \mathrm{~min}$.

(5) Extracted thylakoid membranes were centrifuged at $9000 \times g$ at $4{ }^{\circ} \mathrm{C}$ for $5 \mathrm{~min}$. 
(6) Thylakoid pellets were re-suspended in EDTA washing buffer, and then centrifuged at $9000 \times \mathrm{g}$ at $4{ }^{\circ} \mathrm{C}$ for $5 \mathrm{~min}$. The precipitate was resuspended in HM buffer and stored at $-80^{\circ} \mathrm{C}$ as a thylakoid fraction.

\section{References}

1. Briat, J.F.; Dubos, C.; Gaymard, F. Iron nutrition, biomass production, and plant product quality. Trends Plant Sci. 2015, 20, 33-40. [CrossRef] [PubMed]

2. Amunts, A.; Nelson, N. Plant Photosystem I Design in the Light of Evolution. Structure 2009, 17, 637-650. [CrossRef]

3. Hantzis, L.J.; Kroh, G.E.; Jahn, C.E.; Cantrell, M.; Peers, G.; Pilon, M.; Ravet, K. A Program for Iron Economy during Deficiency Targets Specific Fe Proteins. Plant Physiol. 2018, 176, 596-610. [CrossRef]

4. Michel, K.P.; Pistorius, E.K. Adaptation of the Photosynthetic Electron Transport Chain in Cyanobacteria to Iron Deficiency: The Function of IdiA and IsiA. Physiologia Plantarum; Wiley: Hoboken, NJ, USA, 2004; Volume 120, pp. 36-50.

5. Kroh, G.E.; Pilon, M. Regulation of Iron Homeostasis and Use in Chloroplasts. Int. J. Mol. Sci. 2020, 21, 3395. [CrossRef]

6. Loeppert, R.H. Reactions of iron and carbonates in calcareous soils. J. Plant Nutr. 1986, 9, 195-214. [CrossRef]

7. Lindsay, W.L. Chemical Equilibria in Soils; Wiley Interscience: New York, NY, USA, 1979.

8. Marschner, H.; Romheld, V.; Kissel, M. Different strategies in higher plants in mobilization and uptake of iron. J. Plant Nutr. 1986, 9, 695-713. [CrossRef]

9. Bashir, K.; Nishizawa, N.K. Deoxymugineic Acid Synthase. Plant Signal. Behav. 2006, 1, 290-292. [CrossRef]

10. Takagi, S.; Kamei, S.; Yu, M. Efficiency of iron extraction from soil by mugineic acid family phytosiderophores. J. Plant Nutr. 1988, 11, 643-651. [CrossRef]

11. Higuchi, K.; Watanabe, S.; Takahashi, M.; Kawasaki, S.; Nakanishi, H.; Nishizawa, N.K.; Mori, S. Nicotianamine synthase gene expression differs in barley and rice under Fe-deficient conditions. Plant J. 2001, 25, 159-167. [CrossRef] [PubMed]

12. Maruyama, T.; Higuchi, K.; Yoshida, M.; Tadano, T. Comparison of Iron Availability in Leaves of Barley and Rice. Soil Sci. Plant Nutr. 2005, 46, 1035-1042. [CrossRef]

13. Saito, A.; Iino, T.; Sonoike, K.; Miwa, E.; Higuchi, K. Remodeling of the Major Light-Harvesting Antenna Protein of PSII Protects the Young Leaves of Barley (Hordeum vulgare L.) from Photoinhibition under Prolonged Iron Deficiency. Plant Cell Physiol. 2010, 51, 2013-2030. [CrossRef] [PubMed]

14. Hirai, M.; Higuchi, K.; Sasaki, H.; Suzuki, T.; Maruyama, T.; Yoshiba, M.; Tadano, T. Contribution of iron associated with highmolecular-weight substances to the maintenance of the SPAD value of young leaves of barley under iron-deficient conditions. Soil Sci. Plant Nutr. 2007, 53, 612-620. [CrossRef]

15. Higuchi, K.; Saito, A.; Mikami, Y.; Miwa, E. Modulation of macronutrient metabolism in barley leaves under iron-deficient condition. Soil Sci. Plant Nutr. 2011, 57, 233-247. [CrossRef]

16. Higuchi, K.; Iwase, J.; Tsukiori, Y.; Nakura, D.; Kobayashi, N.; Ohashi, H.; Saito, A.; Miwa, E. Early senescence of the oldest leaves of Fe-deficient barley plants may contribute to phytosiderophore release from the roots. Physiol. Plant. 2014, 151, 313-322. [CrossRef]

17. Mikami, Y.; Saito, A.; Miwa, E.; Higuchi, K. Allocation of Fe and ferric chelate reductase activities in mesophyll cells of barley and sorghum under Fe-deficient conditions. Plant Physiol. Biochem. 2011, 49, 513-519. [CrossRef] [PubMed]

18. Saito, A.; Shimizu, M.; Nakamura, H.; Maeno, S.; Katase, R.; Miwa, E.; Higuchi, K.; Sonoike, K. Fe deficiency induces phosphorylation and translocation of Lhcb1 in barley thylakoid membranes. FEBS Lett. 2014, 588, 2042-2048. [CrossRef] [PubMed]

19. Pourkheirandish, M.; Hensel, G.; Kilian, B.; Senthil, N.; Chen, G.; Sameri, M.; Azhaguvel, P.; Sakuma, S.; Dhanagond, S.; Sharma, R.; et al. Evolution of the Grain Dispersal System in Barley. Cell 2015, 162, 527-539. [CrossRef] [PubMed]

20. Fujii, M.; Yokosho, K.; Yamaji, N.; Saisho, D.; Yamane, M.; Takahashi, H.; Sato, K.; Nakazono, M.; Ma, J.F. Acquisition of aluminium tolerance by modification of a single gene in barley. Nat. Commun. 2012, 3, 713. [CrossRef]

21. Xia, Y.; Li, R.; Bai, G.; Siddique, K.H.M.; Varshney, R.K.; Baum, M.; Yan, G.; Guo, P. Genetic variations of HvP5CS1 and their association with drought tolerance related traits in barley (Hordeum vulgare L.). Sci. Rep. 2017, 7, 1-10. [CrossRef]

22. Hemshrot, A.; Poets, A.M.; Tyagi, P.; Lei, L.; Carter, C.K.; Hirsch, C.N.; Li, L.; Brown-Guedira, G.; Morrell, P.L.; Muehlbauer, G.J.; et al. Development of a Multiparent Population for Genetic Mapping and Allele Discovery in Six-Row Barley. Genetics 2019, 213, 595-613. [CrossRef]

23. Hikosaka, K. Interspecific difference in the photosynthesis?nitrogen relationship: Patterns, physiological causes, and ecological importance. J. Plant Res. 2004, 117, 481-494. [CrossRef] [PubMed]

24. Sage, R.F.; Pearcy, R.W. The Nitrogen Use Efficiency of C3 and C4 Plants. Plant Physiol. 1987, 84, 954-958. [CrossRef] [PubMed]

25. Makino, A.; Mae, T.; Ohira, K. Differences between wheat and rice in the enzymic properties of ribulose-1,5-bisphosphate carboxylase/oxygenase and the relationship to photosynthetic gas exchange. Planta 1988, 174, 30-38. [CrossRef] [PubMed]

26. Boogaard, R.V.D.; Kostadinova, S.; Veneklaas, E.; Lambers, H. Association of water use efficiency and nitrogen use efficiency with photosynthetic characteristics of two wheat cultivars. J. Exp. Bot. 1995, 46, 1429-1438. [CrossRef]

27. Guo, R.; Sun, S.; Liu, B. Difference in leaf water use efficiency/photosynthetic nitrogen use efficiency of Bt-cotton and its conventional peer. Sci. Rep. 2016, 6, 33539. [CrossRef]

28. Hassani, A.; Azapagic, A.; Shokri, N. Predicting long-term dynamics of soil salinity and sodicity on a global scale. Proc. Natl. Acad. Sci. USA 2020, 117, 33017-33027. [CrossRef] 
29. FAO/IIASA/ISRIC/ISS-CAS/JRC. Harmonized World Soil Database (Version 1.2); FAO: Rome, Italy; IIASA: Laxenburg, Austria, 2012.

30. Zivcak, M.; Brestic, M.; Kalaji, H.M.; Govindjee, G. Photosynthetic responses of sun- and shade-grown barley leaves to high light: Is the lower PSII connectivity in shade leaves associated with protection against excess of light? Photosynth. Res. 2014, 119, 339-354. [CrossRef]

31. Amann, K.; Lezhneva, L.; Wanner, G.; Herrmann, R.G.; Meurer, J. ACCUMULATION OF PHOTOSYSTEM ONE1, a Member of a Novel Gene Family, Is Required for Accumulation of [4Fe-4S] Cluster-Containing Chloroplast Complexes and Antenna Proteins. Plant Cell 2004, 16, 3084-3097. [CrossRef]

32. Baker, N.R. Chlorophyll fluorescence: A probe of photosynthesis in vivo. Annu. Rev. Plant Biol. 2008, 59, 89-113. [CrossRef]

33. Yuasa, K.; Shikata, T.; Kitatsuji, S.; Yamasaki, Y.; Nishiyama, Y. Extracellular secretion of superoxide is regulated by photosynthetic electron transport in the noxious red-tide-forming raphidophyte Chattonella antiqua. J. Photochem. Photobiol. B Biol. 2020, 205, 111839. [CrossRef]

34. Lezhneva, L.; Amann, K.; Meurer, J. The universally conserved HCF101 protein is involved in assembly of [4Fe-4S]-clustercontaining complexes in Arabidopsis thaliana chloroplasts. Plant J. 2003, 37, 174-185. [CrossRef] [PubMed]

35. Yamazaki, H.; Tasaka, M.; Shikanai, T. PPR motifs of the nucleus-encoded factor, PGR3, function in the selective and distinct steps of chloroplast gene expression inArabidopsis. Plant J. 2004, 38, 152-163. [CrossRef] [PubMed]

36. Kono, M.; Terashima, I. Elucidation of Photoprotective Mechanisms of PSI Against Fluctuating Light photoinhibition. Plant Cell Physiol. 2016, 57, 1405-1414. [CrossRef] [PubMed]

37. Yamori, W.; Makino, A.; Shikanai, T. A physiological role of cyclic electron transport around photosystem I in sustaining photosynthesis under fluctuating light in rice. Sci. Rep. 2016, 6, 20147. [CrossRef]

38. Baxter, I.R.; Vitek, O.; Lahner, B.; Muthukumar, B.; Borghi, M.; Morrissey, J.; Guerinot, M.L.; Salt, D.E. The leaf ionome as a multivariable system to detect a plant's physiological status. Proc. Natl. Acad. Sci. USA 2008, 105, 12081-12086. [CrossRef]

39. Millaleo, R.; Reyes-Díaz, M.; Alberdi, M.; Ivanov, A.G.; Krol, M.; Hüner, N.P.A. Excess manganese differentially inhibits photosystem I versus II inArabidopsis thaliana. J. Exp. Bot. 2013, 64, 343-354. [CrossRef]

40. Eroglu, S.; Meier, B.; von Wirén, N.; Peiter, E. The Vacuolar Manganese Transporter MTP8 Determines Tolerance to Iron Deficiency-Induced Chlorosis in Arabidopsis. Plant Physiol. 2016, 170, 1030-1045. [CrossRef]

41. Russell, J.; Mascher, M.; Dawson, I.K.; Kyriakidis, S.; Calixto, C.; Freund, F.; Bayer, M.; Milne, I.; Marshall-Griffiths, T.; Heinen, S.; et al. Exome sequencing of geographically diverse barley landraces and wild relatives gives insights into environmental adaptation. Nat. Genet. 2016, 48, 1024-1030. [CrossRef]

42. Higuchi, K.; Ono, K.; Araki, S.; Nakamura, S.; Uesugi, T.; Makishima, T.; Ikari, A.; Hanaoka, T.; Sue, M. Elongation of barley roots in high-pH nutrient solution is supported by both cell proliferation and differentiation in the root apex. Plant Cell Environ. 2017, 40, 1609-1617. [CrossRef]

43. Gentili, R.; Ambrosini, R.; Montagnani, C.; Caronni, S.; Citterio, S. Effect of Soil pH on the Growth, Reproductive Investment and Pollen Allergenicity of Ambrosia artemisiifolia L. Front. Plant Sci. 2018, 9, 1335. [CrossRef]

44. Taylor, S.H.; Ripley, B.S.; Woodward, F.I.; Osborne, C.P. Drought limitation of photosynthesis differs between C3 and C4 grass species in a comparative experiment. Plant Cell Environ. 2010, 34, 65-75. [CrossRef] [PubMed]

45. Vogan, P.J.; Sage, R.F. Water-use efficiency and nitrogen-use efficiency of C3-C4 intermediate species of Flaveria Juss. (Asteraceae). Plant Cell Environ. 2011, 34, 1415-1430. [CrossRef] [PubMed]

46. Majeran, W.; van Wijk, K.J. Cell-type-specific differentiation of chloroplasts in C4 plants. Trends Plant Sci. 2009, 14, 100-109. [CrossRef]

47. De Miguel, M.; Cabezas, J.A.; de María, N.; Sánchez-Gómez, D.; Guevara, M.Á.; Vélez, D.; Sáez-Laguna, E.; Díaz, L.M.; Mancha, J.A.; Barbero, M.-C.; et al. Genetic control of functional traits related to photosynthesis and water use efficiency in Pinus pinaster Ait. drought response: Integration of genome annotation, allele association and QTL detection for candidate gene identification. BMC Genom. 2014, 15, 1-19. [CrossRef] [PubMed]

48. Lü, H.; Yang, Y.; Li, H.; Liu, Q.; Zhang, J.; Yin, J.; Chu, S.; Zhang, X.; Yu, K.; Lv, L.; et al. Genome-Wide Association Studies of Photosynthetic Traits Related to Phosphorus Efficiency in Soybean. Front. Plant Sci. 2018, 9, 1226. [CrossRef] [PubMed]

49. Cuello, J.; Quiles, M.J.; Albacete, M.E.; Sabater, B. Properties of a Large Complex with NADH Dehydrogenase Activity from Barley Thylakoids. Plant Cell Physiol. 1995, 36, 265-271. [CrossRef]

50. Caffarri, S.; Croce, R.; Breton, J.; Bassi, R. The Major Antenna Complex of Photosystem II Has a Xanthophyll Binding Site Not Involved in Light Harvesting. J. Biol. Chem. 2001, 276, 35924-35933. [CrossRef]

51. Porra, R.; Thompson, W.; Kriedemann, P. Determination of accurate extinction coefficients and simultaneous equations for assaying chlorophylls a and $\mathrm{b}$ extracted with four different solvents: Verification of the concentration of chlorophyll standards by atomic absorption spectroscopy. Biochim. et Biophys. Acta (BBA) Bioenerg. 1989, 975, 384-394. [CrossRef]

52. Shaaf, S.; Bretani, G.; Biswas, A.; Fontana, I.M.; Rossini, L. Genetics of barley tiller and leaf development. J. Integr. Plant Biol. 2019, 61, 226-256. [CrossRef]

53. Makiko, C.; Honda, I.; Zeniya, H.; Yoneyama, K.; Saisho, D.; Takeda, K.; Takatsuto, S.; Hoshino, T.; Watanabe, Y. A Semidwarf Phenotype of Barley uzu Results from a Nucleotide Substitution in the Gene Encoding a Putative Brassinosteroid Receptor. Plant Physiol. 2003, 133, 1209-1219. [CrossRef] 
54. Saisho, D.; Tanno, K.-I.; Chono, M.; Honda, I.; Kitano, H.; Takeda, K. Spontaneous Brassinolide-insensitive Barley Mutants 'uzu' Adapted to East Asia. Breed. Sci. 2004, 54, 409-416. [CrossRef]

55. Gooding, M.; Addisu, M.; Uppal, R.K.; Snape, J.W.; Jones, H. Effect of wheat dwarfing genes on nitrogen-use efficiency. J. Agric. Sci. 2012, 150, 3-22. [CrossRef]

56. Wang, B.; Li, G.; Zhang, W.-H. Brassinosteroids are involved in Fe homeostasis in rice (Oryza sativa L.). J. Exp. Bot. 2015, 66, 2749-2761. [CrossRef] [PubMed] 